\title{
REDUCTION IN REMOTENESS DISTINCTIONS AND RECONFIGURATION IN THE BEMBA PAST \\ TENSE $^{1}$ \\ NANCY C. KULA \\ University of Essex
}

\begin{abstract}
Bantu languages are well-known for having multiple remoteness distinctions in both the past and the future. This paper looks at the 4-way remoteness distinction of Bemba (central Bantu) showing that the system is undergoing change that is resulting in the loss of an intermediate past tense, by merger with the remote past. Two factors are central in driving this change; a merger of forms by tone loss and neutralisation and a shift in the scope of semantic function. Because the Bemba tense-aspect system manifests the so-called conjoint-disjoint alternation, there is also some reconfiguration of the TA system that accompanies the merger. The different factors involved in this change are unified under a cognitive multi-dimensional approach to tense, which is here extended to account for language change in tense systems.
\end{abstract}

\section{INTRODUCTION}

Tense systems in Bantu are renowned for being rich and complex, usually involving a number of pasts and futures (Dahl 1985, Nurse 2003, Nurse and Philippson 2006, Nurse 2008). In line with this observation Nurse (2003, 2008) and Nurse and Philippson's (2006) large scale studies of tense and aspect in Bantu show that most Bantu languages encode several degrees of past and future reference, with typically more distinctions in the past than the future. These studies broadly show that the majority of Bantu languages have two to three remoteness distinctions, with a smaller number of languages showing one past and yet a fewer number showing four distinctions in the past. In the future a similar large number of languages show either one or two future distinctions, with fewer languages showing three future tenses. ${ }^{2}$ In this context, Bemba, the focus of this paper, is on the higher scale of complexity with historically four past tenses and three futures as described in Sharman (1956) and Sharman \& Meeussen (1955) (see also Hoch 1963, Givón 1972, Mann 1977, van Sambeek 1955). The four pasts contrast: an immediate past, a today past, an intermediate or recent past, and a remote past. The future contrasts an immediate future, a future within today, and a future after today.

This paper focuses on the past tense system which is undergoing a change involving the intermediate past, which is gradually being lost. The remote past is emerging as the main tense used to refer to all events before today. This change is investigated both from a morphological and semantic perspective, demonstrating how

\footnotetext{
${ }^{1}$ This work was presented at a meeting of the Philological Society in January 2013; at Bantu 5 in Paris (2013); at the Tense-Aspect Workshop in Essex in 2014; and at the Department of Linguistics, University of Cape Town (2014).

${ }^{2}$ In his investigation of 120+ Bantu languages Nurse (2003: 100) notes that for the past tense a two and three-way contrast are the most frequent with 49 and 47 languages, respectively, showing this pattern. 23 languages have one past and 16 have 4 pasts. There are reports of some Grassfields languages with 5 pasts and 5 futures and western Gogo may also be an example. For futures, one future is the most common with 50 languages, followed by two futures (48 languages) and finally those with three futures (20 languages).
} 
the two intermediate past tense allomorphs divide between obsoleteness of one allomorph and the expansion in semantic scope of the other. This leads to an increase in the number of morphemes used to express the remote past. The remote past is best understood as semantically determined by context, rather than as denoting a fixed time-range on a linear timeline. The goal of this paper is to trace this change and hypothesize on the possible factors driving it. It will be argued that a number of different motivations play a role in the ongoing merger of the intermediate and the remote past. These include phonological form (via tonal loss and neutralization), morphological form, semantic function, and paradigm uniformity. Furthermore, Botne (2012) and Botne \& Kershner's (2008) cognitive approach to tense will be extended to draw these different factors together under one unified analysis.

The paper is organised as follows; section 2 provides background information on Bemba and its past and future tense paradigms; section 3 provides a discussion of four different factors that have contributed to the merger of the intermediate and the remote past; section 4 offers an analysis that models diachronic change within a multi-dimensional view of tense, providing a unified analysis of the different factors; and section 5 offers some concluding remarks.

\section{BEMBA BACKGROUND AND TENSE SYSTEM}

Bemba is a central Bantu language (of zone M in Guthrie's (1967-71) classification, see also Maho 2009) with more than 2 million first language speakers (and an equal or larger number of second language speakers). It is mainly spoken in Zambia but there are also speakers in the DRC. There are a number of dialects but three main ones: Luapula Bemba in the northwest, Northern Bemba in the north and Copperbelt Bemba in central Zambia. This paper will have nothing to say about Luapula Bemba.

Northern Bemba (NB) is considered as representative of the original Bemba inhabitants, descended from the Luba-Lunda empire. The central dialect from Kasama is what is generally reported in the literature, and this is what will be considered under $\mathrm{NB}$ here. Copperbelt Bemba (CB) results from migrations from the NB area from around the $1920 \mathrm{~s}$, resulting in settlements in the mining regions of central Zambia (called the Copperbelt). ${ }^{3}$ Morphologically NB and CB are (almost) identical but show variation in lexicon and phonology, particularly tone. No investigations on differences in morpho-syntax have been made. Bemba contrasts lexically high-toned and toneless morphemes with examples of minimal pairs where the contrast in meaning is carried by tone. The tone bearing unit is the mora and high tones are subject to a number of spreading processes, some of which will be relevant and discussed at the appropriate junctures.

Bemba is described in reference grammars (Hoch 1963, van Sambeek 1955) as having 4 past tenses, with a close symmetrical distribution with the future, although the latter only has 3 contrasts. These are shown in (1) and (2) below. The tenses are

\footnotetext{
${ }^{3}$ My use and reference to Copperbelt Bemba here refers not to what has been termed "Town Bemba" (Kashoki 1972) which emerged as a language variety on the mines as a result of language mixing with significant input from Bemba. Further studies of Town Bemba (Spitulnik 1998, Kabinga 2010) show it to be an urban variety spoken by a population wider than only those of Bemba descent and that is generally in continuous fluctuation and change. By Copperbelt Bemba I refer to the speech of Bemba speakers settled in the Copperbelt who consider their ancestry to emerge from the original inhabitants in the North. There are naturally intersections of the two groups but CB data for this study were only collected from Bemba native speakers with a clear Bemba lineage. The probably shifting boundaries between what is referred to here as $\mathrm{CB}$ and Town Bemba deserve more detailed investigation but goes beyond the scope of the current paper.
} 
sequentially denoted with respect to their relative distance from the current time (the time at which a speech event occurs), with the past preceding the current time and the future following it. We return to these characterisations in later discussion.

\section{(1) Bemba Pasts}

P1 for an immediate past

P2 for a past of today

P3 for a recent past of within a few days ago

$\mathrm{P} 4$ for a remote past

(2) Bemba Futures

F1 for an immediate future

F2 for a future of today

F3 for a future after today

The past tenses show the so-called conjoint-disjoint alternation which is a morphological alternation in verb forms of particular tenses, correlating with particular semantic interpretations and distributional properties (see Hyman \& van der Wal to appear, Kula to appear, for discussion). Five tenses show this alternation in Bemba as shown in table 1. The important point for the present is that P3 and P4 have two distinct morphological markers in the perfective contrasting conjoint and disjoint forms. This will be the focus in the ensuing discussion.

\begin{tabular}{|c|c|c|c|c|c|c|c|c|c|c|c|c|}
\hline \multirow[b]{2}{*}{ CONJOINT } & \multicolumn{2}{|c|}{$\begin{array}{l}\text { PRESENT / } \\
\text { HABITUAL }\end{array}$} & \multicolumn{2}{|c|}{$\begin{array}{c}\text { P1 } \\
\text { (PERFECTIVE) }\end{array}$} & \multicolumn{2}{|c|}{$\begin{array}{c}\text { P3 } \\
\text { (PERFECTIVE) }\end{array}$} & \multicolumn{2}{|c|}{$\begin{array}{c}\text { P4 } \\
\text { (PERFECTIVE) }\end{array}$} & \multicolumn{2}{|c|}{$\begin{array}{c}\text { P4 } \\
\text { (ANTERIOR) }\end{array}$} & \multicolumn{2}{|c|}{$\begin{array}{c}\text { ZERO } \\
\text { (ANTERIOR) }\end{array}$} \\
\hline & $-\varnothing-$ & $-a$ & -á- & $-a$ & -á- & -ile & $-a-$ & -ile & $-a-$ & $-a$ & $-\varnothing-$ & -ile \\
\hline DISJOINT & -la- & $-a$ & -áa- & $-a$ & -álii- & $-a$ & -alí- & -ile & -alí- & $-a$ & náa- & \\
\hline
\end{tabular}

Table 1: Conjoint-disjoint forms in Bemba

As exemplified in table 1 the tense forms come in two parts: an initial and a final with the final marked by either $-a$ or -ile. Both parts contribute to the interpretation of the tense (see Nurse 2003, et seq.). These tense markers occur within the Bantu verbal template of SM-TAM-(OM)-VerbStem-FV with the initial occupying a TAM position and the final the FV position. ${ }^{4}$ A table of the Bemba TA system is given in Appendix 1 based on Nurse (2008).

For a better understanding of the remainder of the paper, I give a brief discussion of the conjoint-disjoint alternation in the following sub-section but the reader is directed to Kula (to appear) for a fuller exposition.

\subsection{Conjoint-Disjoint in the TAM system}

The classic contemporary work on the conjoint-disjoint alternation in Bantu is Creissels (1996) (see also Creissels 2012), who discusses the alternation in Tswana. Creissels associates the alternation with new information focus, namely, that conjoint

\footnotetext{
${ }^{4}$ The following abbreviations will be used: $\mathrm{SM}=$ Subject Marker; TAM = Tense Aspect Mood; OM = Object Marker; FV = Final Vowel (of verb stem); FUT = Future tense (FUT1/2/3 = different degrees of the future); $\mathrm{P} 1 / 2 / 3 / 4=$ different degrees of the Past tense; $\mathrm{LOC}=$ Locative; $\mathrm{HAB}=$ habitual; $\mathrm{PL}=$ plural; $\mathrm{SG}=$ singular; $\mathrm{DISJ}=$ disjoint; $\mathrm{CONJ}=$ conjoint; $\mathrm{PERF}=$ perfective; $\mathrm{DEM}=$ demonstrative $(\mathrm{DEM} 1 / 2 / 3 / 4=$ different DEM contrasts); $\mathrm{AUG}=$ augment; $\mathrm{COP}=$ copular; $\mathrm{RCD}=$ referential concord; $\mathrm{COMPL}=$ complementizer; REL = relativiser; $\mathrm{Q}=$ question particle; CAUS $=$ causative; and $\mathrm{H}=$ high tone. Acute accents mark high tone while low tone will be unmarked.
} 
forms indicate following new information. By contrast, disjoint forms, if they have a following constituent, indicate old or backgrounded information. There are different views on this in the literature and it has become apparent and accepted that the alternation is associated with different properties in different Bantu languages. While information structure is a recurrent property, it has also been argued that the alternation indicates syntactic constituency in some languages. See Buell (2006), Hyman (2012), Meeussen (1959), Nurse (2006), van der Wal (2006, 2009, 2011), Yoneda (2009), among others, for discussion of the conjoint-disjoint alternation in different Bantu languages. Hyman \& van der Wal (to appear), and papers therein, provide a cross-Bantu overview.

In Bemba the conjoint-disjoint alternation indicates information structure (see earlier descriptions in Givón 1975, Sharman and Meeussen 1955, and Sharman 1956). Conjoint verb forms are exclusively used in contexts where the following constituent is either new information or contrastively focused. Disjoint forms are used when the verb is part of the focus. Consider the example in (3) below of the present/habitual with an all low-toned verb form. (3a) shows the conjoint form with a zero tense marked verb requiring a following constituent, which is contrastively focused in this case. If the conjoint verb form is used without a following constituent, the sentence is ungrammatical (3b). In the disjoint form in (3c) the verb is new information, providing an answer to a question like 'what do you do all day?' (3d) can have two interpretations (depending on the associated phonological phrasing), with the postverbal constituent as either part of the focus, in which case the whole VP provides new information, or as outside the focus, in which case the object is an afterthought. In this case disjoint forms always include the verb as part of new information in VP focus, which consists of either only the verb or the verb and a complement.

(3) Conjoint-disjoint alternation in the present/habitual

$\begin{array}{lll}\text { (3a) } & \text { tu-ø-luk-a imishishi } & \text { CONJOINT } \\ & \text { 2PL-ø-plait-FV 4hair } & \\ & \text { 'We plait hair/what we plait is hair (not something else)' } \\ \text { (3b) } & * \text { tu-ø-luk-a } & \\ & & \\ \text { (3c) } & \text { tu-la-luk-a } & \\ & \text { 2PL-DISJ-plait-FV } & \\ & \text { 'We plait' } & \\ \text { (3d) } & \text { tu-la-luk-a imoINT } \\ & \text { 2PL-DISJ-plait-FV 4hair } & \\ & \text { 'We plait hair' } & \end{array}$

The facts in (3) lead to the distributional properties often associated with the conjoint-disjoint alternation, namely, that disjoint forms can occur final in a main clause (3c), while conjoint forms cannot (3b). An additional factor in the Bemba conjoint-disjoint alternation is that conjoint-disjoint forms directly mirror phonological phrasing, so that focused constituents occur phonological phrase final. Two tone spreading patterns are important diagnostics for phonological phrasing in Bemba. Unbounded rightward high tone spreading, which spreads a high tone to the end of a verb form, indicates an immediately following phonological phrase boundary. If there is no immediately following phonological phrase boundary after the verb, then high tone on the verb form undergoes bounded high tone spreading. 
Bounded high tone spreading is either ternary $(\mathrm{CB})$ or binary (NB). See Bickmore \& Kula (2013), Kula \& Bickmore (2015) for details. Since, as discussed, focused constituents occur phonological phrase final, disjoint verb forms show unbounded high tone spreading. By contrast conjoint forms show bounded high tone spreading (in all those cases where there is a high tone on the verb form).

Thus conjoint-disjoint forms in Bemba are marked by different morphemes on the verb and contrast different information structure that is associated with contrasting distributional patterns and phonological phrasing. The conjoint-disjoint alternation therefore makes no aspectual contribution to the verb forms which are contrasted. These are the properties that will be assumed in all reference to the conjoint-disjoint alternation in the remainder of the paper.

With this background, let us now consider in more detail the change in the past tense paradigm which is the focus of this paper.

\subsection{Change relating to $P 3$ in Bemba}

The affirmative tenses given in table 2 below will be the focus of the paper. Table 2 shows the morphological forms of P1-P4 and F1-F3.

\begin{tabular}{|l|ll|ll|l|ll|}
\hline TENSE & \multicolumn{2}{|c|}{ CONJ } & \multicolumn{2}{c|}{ DISJ } & & \multicolumn{2}{|c|}{ NO CONTRAST } \\
\hline P1 & -á- & -a & -áa- & -a & F1 & -áláa- & -a \\
\hline P2 & \multicolumn{2}{|c|}{-ácí- } & -a & F2 & -lée- & -a \\
\hline P3 & -á- & -ile & -álii- & -a & \multirow{2}{*}{ F3 } & -ka- & -a \\
\hline P4 & -a- & -ile & -alí- & -ile & & & \\
\hline
\end{tabular}

Table 2: Bemba Past and Future simple (perfective) tense markers

From table 2 we can see that the initial part of the past tense form (that occurs after the subject marker and before the optional object marker in the Bantu verb) is mainly marked only by $-a$ - in the conjoint form for P1, P3 and P4. P1 and P3 are in addition high-toned. P3 and P4 are only distinguished by a difference in tone on the initial $-a-$ with both having the -ile ending. The disjoint forms of P3 and P4 are more distinct with different endings as well as tonal and vowel length differences on the initial. In $\mathrm{P} 1$ there is a minimal difference between the conjoint and disjoint forms indicated by vowel length, while P2 is a tense that does not have the conjoint-disjoint alternation, just like all the future forms. ${ }^{5}$

Following the works of, for example, Comrie (1976, 1985), Reichenbach (1947), and Smith (1997), the traditional assumption in Bantu has been to treat these different past/future forms as denoting linear temporal reference. Nurse (2003) thus employs a timeline divided at different points, as correlating to the number of tenses expressed

\footnotetext{
${ }^{5}$ Earlier work of Sharman and Meeussen (1955) notes that F1 previously used identical forms to P1, namely $-a-a$ for the conjoint and -áa- $-a$ for the disjoint. I have found radically diminished use of these forms in contemporary Bemba, both in the NB and CB dialects, although use in restricted contexts can occur. -láa- in the current forms is clearly derived from the F1 progressive which seems to have subsumed the simple tense forms. Similarly, it is probable that the F2 form -leee- also derives from the present progressive which is still in use. Botne (pc) points out to me that this dual use of -lée- is problematic particularly in standard representations of tense, and its exposition will not only elaborate the future tenses but also lead to a better understanding of the past tenses. This work must be left for future research at present but see some discussion later in section 4. See appendix A for the Bemba TA system.
} 
in different languages. These can be illustrated for the past tense as in table 3 below, based on Nurse (2008). This illustration is drawn from Kiso (2012).

Table 3 illustrates 8 different possible language types and crucially shows different systems within a 2-way, 3-way or 4-way past tense contrast, determined by the position at which the postulated timeline is divided. Within this system Bemba would be a type of system 8 , with P3 modified to 'hesternal + a few days earlier'. ${ }^{6} \mathrm{We}$ will return to this system in section 4 in view of the challenges this perspective faces in explaining the reduction and reconfiguration in remoteness distinctions that Bemba is undergoing.

\begin{tabular}{|c|c|c|c|c|}
\hline System & $\mathrm{P} 1$ & $\mathrm{P} 2$ & P3 & $\mathrm{P} 4$ \\
\hline $\begin{array}{l}1 \\
2 \\
3\end{array}$ & $\begin{array}{l}\text { hodiernal } \\
\text { hodiernal }+ \text { hesternal } \\
\text { recent }\end{array}$ & $\begin{array}{l}\text { non-hodiernal } \\
\text { earlier than P1 } \\
\text { remote }\end{array}$ & & \\
\hline $\begin{array}{l}4 \\
5 \\
6 \\
7\end{array}$ & $\begin{array}{l}\text { hodiernal } \\
\text { hodiernal } \\
\text { immediate } \\
\text { immediate (+ few } \\
\text { days earlier) } \\
\end{array}$ & $\begin{array}{l}\text { hesternal } \\
\text { hesternal+ few days } \\
\text { hodiernal } \\
\text { hodiernal + } \\
\text { hesternal }\end{array}$ & $\begin{array}{l}\text { earlier than P2 } \\
\text { earlier than P2 } \\
\text { non-hodiernal } \\
\text { earlier than P2 }\end{array}$ & \\
\hline 8 & $\begin{array}{l}\text { immediate }(+ \text { few } \\
\text { days earlier })\end{array}$ & hodiernal & hesternal & earlier than P3 \\
\hline
\end{tabular}

Table 3: Remoteness distinctions in Bantu past tenses (Kiso 2012: 57)

Recent findings based on fieldwork conducted between 2011 and 2012 show that the conjoint form of P3 is almost totally lost in Bemba, with P4 taking over as the only tense used to refer to events before today in the conjoint form. ${ }^{7}$ This means the past tense system is moving towards becoming a type 6 language, in this respect. Consider the partial paradigm for the verb to learn in (4) illustrating the merger under discussion. ${ }^{8}$ Lexical high tones are underlined, including Melodic Highs (grammatical tones associated with particular TAMs, here the final tones of the verb in P1, P3 and P4, see discussion below). Only lexical high tones are shown in (4a-b) for ease of exposition, i.e. no high spreading is shown. (High tone will be abbreviated as $\mathrm{H}$ and Melodic Highs as MH in the remainder of the paper).

(4) Past (conjoint) paradigm for ukusambilila 'to learn'

$\begin{array}{rlr}\text { (4a) P1: } & \text { na-á-sambílíl-á } & \text { ukuleenga } \\ & \text { 1sG.SM-P1-learn-FV 15draw } \\ & \text { 'I (have just) learnt to draw' }\end{array}$

\footnotetext{
${ }^{6}$ Nurse and Philippson (2006) describe this type of system, where P3 involves 'hesternal + a few days' as atypical, citing Lubuku as another Bantu language showing this anomalous pattern, in comparison to other Bantu languages that have 4 pasts and typically show the 'system 8' pattern in table 3.

${ }^{7}$ Data was collected in both Northern (Central, Kasama) and Copperbelt (Ndola) Bemba areas using oral elicitations, story-telling activities and questionnaires. Written questionnaires were specifically used to test particular tense entailments, see later discussion.

${ }^{8} \mathrm{~A}$ verb like finish 'pw-a' which is more punctual works better pragmatically in this case but I use a longer verb (in terms of number of syllables) in order to illustrate the tonal effects better.
} 
(4b)

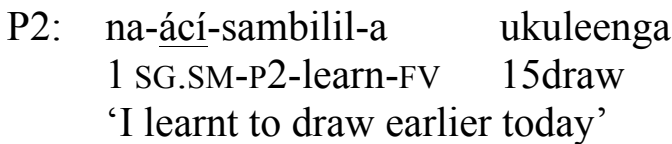

input

(4c) P3: na-á-sambílíílé

1SG.SM-P3-learn.PERF

actual output $(=\mathrm{P} 4)$

na-a-sambílíílé mailo

'I learnt yesterday/some days ago' expected output

mailo $\rightarrow$ na-a-sám! bílíílé mailo $\rightarrow$

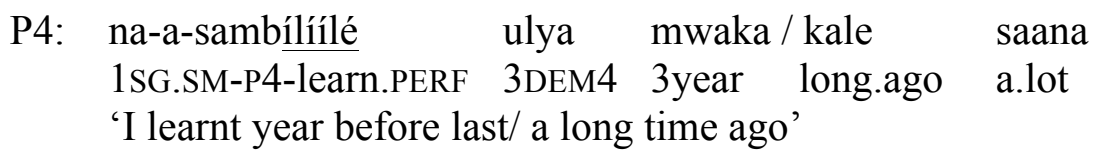

The main difference between P3 and P4 lies in their different tone on the initial part of the tense marker $-a$-. It has been noted elsewhere in Bickmore and Kula (2013) that Bemba does not allow surface rising tones, as seen in the initial part of the P3 form $n a-a-a-s a m b i$ ílílé. Such rising patterns are resolved by preferably shifting the tone to the next syllable or resolving the rise as a level low or level $\mathrm{H}$ depending on what tone follows in the next syllable. In P3 the $\mathrm{H}$ is shifted to the next syllable. A further important point, as noted earlier, is that, like in other Bantu languages, some TAM markers are lexically associated with particular tone or tone patterns (MHs). Melodic Highs are high tones whose presence cannot be explained by the regular tone rules of the language. ${ }^{9}$ The remote past (P4) and all forms with the perfective ending -ile have a $\mathrm{MH}$ from the second vowel of the verb stem (V2) to the final. This is the $\mathrm{H}$ that we see surfacing in P4. P3 ending in -ile will therefore also have the same MH but because of the shifted tone from the preceding syllable we expect a downstep (indicated by superscript !) from two adjacent Hs (in the expected form). ${ }^{10}$ The P3 form in (4c) was, in this respect, historically phonologically distinct from the $\mathrm{P} 4$ form in (4d), by having a downstep where the P4 form does not. The downstepped form of P3 is now being replaced by the P4 form without downstep and thereby renders the forms identical. We return to this analysis in ensuing discussion.

The disjoint form of P3 (-alii- - $a$ in table 2) continues to be used but is currently under fluctuation and can be used in both P3 conjoint and disjoint contexts. Its use in $\mathrm{P} 4$ contexts is much less clear and must be further investigated. We will take up the use of the disjoint P3 form in later discussion and rather initially focus on the almost extinct P3 conjoint form. Fieldwork did not elicit any spontaneous uses of the P3 conjoint form with events relating to P3 contexts (i.e. yesterday, a few days ago and

\footnotetext{
${ }^{9}$ Bickmore \& Kula (2013) note four groups of TAMs in this respect; those without any MH, those with a $\mathrm{MH}$ on V2 to the final, those with a $\mathrm{MH}$ on the final and those with a MH only on V2. V2 is the vowel following the initial vowel of the verb stem. For the current purposes P2, F1, F2, F3 all have no $\mathrm{MH}$ associated to them while P1, P3 and P4 have the V2 to final MH. For an overview on MHs in Bantu see Odden \& Bickmore (2014).

${ }^{10}$ Downstep is the lowering pitch effect seen between two lexical Hs where a $\mathrm{H}$ following another lexical $\mathrm{H}$ is produced at a lower pitch. In many African tone languages downstep is triggered by an intervening low tone but this is not the case in Bemba where it occurs between a derived $\mathrm{H}$ and a following lexical $\mathrm{H}$.
} 
up to a week, though see revision of this idea later) rather given using $\mathrm{P} 4 .{ }^{11}$ Only passive knowledge of the $\mathrm{P} 3$ conjoint form could be established, with some speakers accepting the form when offered and co-relating its use to P3 contexts.

Given the historical relation between $\mathrm{NB}$ and $\mathrm{CB}$, with the latter regarded as possibly influenced by its multilingual setting, it is tempting to think that this change is innovated by $\mathrm{CB}$ and reflects further dialectal divergence. In this case we should expect to see the change predominantly instantiated in $\mathrm{CB}$ but not in NB. Alternatively, as in most ongoing language change, we could look to young speakers as the drivers of this change, in which case we may not necessarily expect a split contrasting the two dialects, but rather that young speakers in both dialects are the most likely to manifest this change. However, both these hypotheses prove wrong with the loss of the $\mathrm{P} 3$ conjoint form attested across all generations and equally in the two dialects. The change is thus more global and can in this sense not be explained by dialectal differences. The paper will aim to establish what factors and motivations may have led to the current shift in the Bemba past tenses. The following section discusses 4 possible motivations for this change: phonological form, morphological form, semantic function, and paradigm uniformity.

\section{MOTIVATIONS FOR THE LOSS OF THE P3 CONJOINT FORM}

This section considers 4 possible reasons for the loss of the P3 conjoint form having to do with tonal interaction, form, function and paradigm uniformity. It will emerge that although each of these factors contribute to the currently observed change under study, no single one can be deemed as the sole factor. Rather, the most satisfactory explanation is one that combines these factors in a uniform analysis. This will be discussed in section 4 .

\subsection{Phonological Factors}

\subsubsection{Tonal neutralization}

Phonological motivation for the merger of P3 and P4 stems from, as already noted, the similarity and minimal phonological difference between the P3 and P4 conjoint forms. This similarity may have led to tonal neutralization of the contrast. ${ }^{12} \mathrm{~A}$ question that arises with respect to the two dialects investigated, which differ in their tonal structure, is how this change came about and how the two tonally differing dialects arrived at the same current position. The relevant forms for this discussion are the conjoint forms of P3 and P4 as depicted in (5) below.

(5) Conjoint forms of P3 and P4

\begin{tabular}{|l|ll|}
\hline P3 & -á- & -ile \\
\hline P4 & -a- & -ile \\
\hline
\end{tabular}

As can be seen P3 and P4 differ only minimally in tone, with the initial $-a$ - marker $\mathrm{H}$-toned in $\mathrm{P} 3$ and low-toned in P4. From this minimal difference particular contexts

\footnotetext{
${ }^{11}$ Since tone is not marked in writing, the use of the P3 conjoint form cannot be evaluated in written texts where it surfaces identically to the P4 conjoint form. Orally elicited folk lore and stories did not show any use of the $\mathrm{P} 3$ conjoint form.

${ }^{12}$ I will use the term merger to refer to the loss of P3 in the conjoint form essentially because the remoteness distinction expressed by $\mathrm{P} 3$ is subsumed by $\mathrm{P} 4$ with no gap left in the system in terms of semantics. See discussion in section 3.2.
} 
can easily result in tonal neutralization rendering P3 and P4 indistinct. Let us consider this in more detail.

Tone in Bemba (both CB and NB), like in most Bantu languages, has both a lexical and grammatical function. $\mathrm{P} 3$ and $\mathrm{P} 4$, as discussed, are both associated with grammatical tone (MHs) of the shape V2-FV i.e. P3 and P4 add high tone from the second vowel of the verb stem (traditionally post root) to the final. Consider the surface (conjoint) forms of P3 and P4 with a low-toned verb below, illustrated with $\mathrm{CB}$, where $X$ represents a following constituent. The underlying form is given in slanting brackets on the right hand side and lexical tones are underlined in the output form on the left. The $\mathrm{MH}$ is given in the underlying form as $\mathrm{H}_{\mathrm{V} 2-\mathrm{FV}}$.
a. P4:
tu-a-loondólwéélé
1 PL-P4-explain.P4
$\mathrm{X}$ 'we explained'
/tu-a-londolol-ile $\mathrm{H}_{\mathrm{V} 2-\mathrm{FV}} /$
b. P3: tu-a-lóó'ndólwéélé
$\mathrm{X}$ 'we explained'
/tu-á-londolol-ile $\mathrm{H}_{\mathrm{V} 2-\mathrm{FV}} /$

In both examples the $1^{\text {st }}$ plural subject marker $t u$ - is low-toned. The grammatical tone associated with $\mathrm{P} 4$ in (6a) renders the output form H-toned from V2 to the final. ${ }^{13}$ The P3 form in (6b) also has the same grammatical tone but, in addition, has a $\mathrm{H}$ on the initial part of the tense marker. This $\mathrm{H}$ shifts to the next syllable and spreads once before it results in a downstep from the following $\mathrm{MH}$ on V2. In this case, the two forms surface as distinct owing to the underlying high tone of $-a$ - in P3. ${ }^{14}$ Consider now the resulting total tonal neutralization between P3 and P4 when the subject marker is H-toned and a low-toned verb is used in CB.
a. P3: bá-á-lú'k-1́lé $\mathrm{X}$
'they wove' /bá-á-luk-ile $\mathrm{H}_{\mathrm{V} 2-\mathrm{FV}} /$
2SM-P3-weave-PERF
b. P4: bá-á-lú'k-ílé $\mathrm{X}$
2SM-P4-weave-PERF 'they wove' /bá-a-luk-ile $\mathrm{H}_{\mathrm{V} 2-\mathrm{FV}} /$

In (7a) the $\mathrm{H}$ of the initial part of $\mathrm{P} 3$ spreads once and results in downstep of the following $\mathrm{MH} .{ }^{15} \mathrm{In}(7 \mathrm{~b})$ the $\mathrm{H}$ of the $\mathrm{SM} b a$ - spreads twice rightwards resulting in a downstep on the MH introduced by P4. In this case P3 and P4 surface as identical and cannot be distinguished. The occurrence of such cases in the grammar, where P3 and $\mathrm{P} 4$ are indistinguishable, can be argued to contribute to the merger between P3 and P4.

Let us further probe how a phonological explanation fares in the two dialects which have differing tonal rules, particularly with respect to bounded spreading i.e.

\footnotetext{
${ }^{13}$ There is a process of imbrication with the perfective suffix -ile in Bemba, which deletes the verb root final $-C$ in this form and fuses the resulting adjacent vowels. See Hyman (1995), Kula (2002) for details on Bemba, and Bastin (1983) on imbrication in general. There is also gliding and vowel lengthening between the SM vowel and the TAM vowel to give twaa-which is not represented in the forms in (6).

${ }^{14}$ As noted earlier, the spreading properties of the H-tone on $-a$ - in (6b) reflects CB. The pattern would be slightly different in NB which avoids violating the OCP (Obligatory Contour Principle, see Odden 1986) i.e. avoids derived adjacent $H$ tone. In this case the form would surface as: [tu-a-lóondólwéélé]. (6a) would be identical to CB in NB.

${ }^{15}$ I assume that fusion takes place between the lexical $\mathrm{H}$ of the subject marker and that of the initial part of P3, explaining why we observe no downstep between lexical Hs. OCP violations in Bemba do not affect adjacent lexical Hs, as seen here between the subject and tense markers in (7a), for example, and must be defined as avoidance of adjacency of a derived $\mathrm{H}$ and a following lexical $\mathrm{H}$. The high tone OCP in Bemba is thus a case of a derived environment effect (DEE), see Kula (2008).
} 
when spreading of a $\mathrm{H}$ does not percolate to the end of the domain. As noted earlier bounded spreading is binary in NB but ternary in CB. In addition, binary spreading in NB will not apply if it will result in adjacency with a following $\mathrm{H}$ tone i.e. if it will result in an OCP violation. This avoidance is illustrated in (8) where the subject marker $\mathrm{H}$ on $-b a ́$ - does not spread onto the future marker $-k a$ - to the right in NB. Spreading to the right in (8) would result in derived $\mathrm{H}$ adjacency which is avoided in NB.

(8) bá-ka-fík-a
2SM-FUT3-arrive-FV $\quad \mathrm{X} \quad$ 'they will arrive' /bá-ka-fík-a/

Thus, the lexical $\mathrm{H}$ of the subject marker $b a$ - which would otherwise spread in (8), does not spread to avoid derived adjacent $\mathrm{Hs}$ with the following lexical $\mathrm{H}$ of the verb root -fik- in NB. By contrast, ternary bounded spreading in CB still applies even if it will result in adjacency with a following $\mathrm{H}$ tone. This results in downstep as shown in (9) where the $\mathrm{H}$ of the subject marker -bá- spreads twice despite the following lexically H-toned verb root.

\section{(9) bá-ká-mú-'lás-a $\quad X \quad$ 'they will hit him' /bá-ka-mu-lás-a/ 2SM-FUT3-1OM-hit-FV}

Despite these differences in bounded spreading rules, both NB and CB independently show tonal neutralization between $\mathrm{P} 3$ and $\mathrm{P} 4$, in particular contexts, as the following examples contrasting the two show. For NB P3 and P4 are distinct in (10a-b), with a low-toned verb and 3sg. object marker -mu-. In (10a) the H spreads from the tense marker - $\dot{a}$ - of P3 to the object marker, but spreads no further because NB has binary spreading. In (10b) where the initial tense marker of $\mathrm{P} 4$ has no $\mathrm{H}, \mathrm{H}$ spreading is triggered by the preceding $\mathrm{H}$-toned subject marker -bá- to the tense marker $-a-$, thus rendering the two forms distinct in this case.

Northern Bemba (NB)

\begin{tabular}{|c|c|c|}
\hline 0) a. P3: & $\begin{array}{l}\text { bá-á-mú-luk-ílé X } \\
\text { 'they plaited him (hair)' }\end{array}$ & /bá-á-mu-luk-ile $\mathrm{H}_{\mathrm{V} 2-\mathrm{FV}}$ \\
\hline b. P4: & $\begin{array}{l}\text { bá-á-mu-luk-ílé X } \\
\text { 'they plaited him (hair)' }\end{array}$ & /bá-a-mu-luk-ile $\mathrm{H}_{\mathrm{V} 2-\mathrm{I}}$ \\
\hline
\end{tabular}

The contrast in (10) is, however, totally neutralized with a H-toned verb as in (11ab). In this case there is no spreading from the initial part of the P3 tense marker in (11a) because NB avoids OCP violations but in (11b) there is binary spreading of the $\mathrm{H}$ of the subject marker, resulting in the identity of the two forms.
(11) a. P3: bá-á-mu-lásh-ílé 'they hit him'
b. P4: bá-á-mu-lásh-ílé

Consider in a similar vein the CB forms below where (12a-b) surface as distinct, with the $\mathrm{H}$ of P3 $-\dot{a}$ - in (12a) spreading in ternary fashion onto the object marker and onto the verb stem. This results in an OCP violation and concomitant downstep with the following grammatical tone (V2-FV pattern). P4 in (12b) does not result in 
downstep because ternary spread stops at the object marker, before the OCP violation is caused. For this reason, the two forms emerge as distinct.

Copperbelt Bemba (CB)

(12) a. P3: bá-á-mú-lúk-'ílé 'they plaited him (hair)' /bá-á-mu-luk-ile $\mathrm{H}_{\mathrm{V} 2-\mathrm{FV}} /$

b. P4: bá-á-mú-luk-ílé /bá-a-mu-luk-ile $\mathrm{H}_{\mathrm{V} 2-\mathrm{FV}}$ /

By contrast in (13) with a H-toned verb root P3 and P4 surface as identical. In (13a) ternary spread from the P3 initial tense marker cannot be fully satisfied and spreads once resulting in downstep of the verb stem $\mathrm{H}$ tone. In (13b) the $\mathrm{H}$ from the subject marker spreads to the toneless P4 initial tense marker and further onto the object marker, fulfilling ternary spread and resulting in downstep of the $\mathrm{H}$ of the verb stem. This final $\mathrm{H}$ spread is identical to (13a) and hence total neutralization.

(13) a. P3: bá-á-mú-'lásh-ílé 'they hit him'

b. P4: bá-á-mú-'ásh-ílé

We thus see that despite different tonal rules in NB and CB they can both result in tonal neutralization (here with $\mathrm{H}$-toned verbs), albeit with different surface forms as (11) for NB compared to (13) for CB show. These data support a merger hypothesis for P3 and P4. Merger would also occur for CB with low toned verbs with a H-toned subject marker and no object marker as shown in (7). Recall also from earlier discussion, that cases where the subject marker is low-toned and which result in a rising tone, which is disallowed in the language, will also result in neutralization, when the rise is resolved by shifting the P3 $\mathrm{H}$ onto the following syllable. This demonstrates that there are a number of scenarios under which tonal neutralization occurs and which would foster the merger of P3 and P4.

\subsubsection{Presence vs. absence of P3 Melodic High}

The preceding neutralization account raises the question whether such identical forms always existed in the language and if so, why a change did not occur sooner. Note also that a neutralization explanation biases particular contexts but not others and thus requires additional explanations to account for the global change. Thus far, we have assumed that both P3 and P4 are associated with the V2-FV MH, but one possibility could be that perhaps P3 was not historically associated with a MH. The reason for thinking this is that the P3 conjoint forms (when they are not merged with P4) are quite distinct in having a consistently significantly higher $\mathrm{H}$ on the verb root, than the P4 forms. The absence of a MH in the P3 forms could provide an explanation for this, if we assume that the $\mathrm{P} 3 \mathrm{H}$ on the verb sounds higher because it has no following Hs i.e. the P3 H shows a greater fall because only low tones follow. This contrasts with the more moderate fall between a $\mathrm{H}$ and a following downstepped $\mathrm{H}$ that we would expect if P3 had a MH. Alternatively, this super high tone could be the result of a 'raised H', a term Sharman and Meeussen (1955) use in reference to some final Hs in NB. Consider the following pitch tracks based on data elicited from a female speaker (NB) who (maintaining the contrast between P3 and P4) produced both P3 and P4 forms for a low-toned and a $\mathrm{H}$-toned verb. The contrasting examples in this case would be as given in (14a-b) for P3 vs. (14c) for P4. $\left({ }^{\uparrow}\right.$ indicates a raised H on the following syllable). 
(14) a. P3: tu-á-loondolweele $X \rightarrow$ tu-a- ${ }^{\uparrow}$ lóóndólweele 'we explained $X$ '

b. P3: tu-á-tóoteele $X \rightarrow$ tu-a- ${ }^{\uparrow}$ tóótééle 'we thanked $X$ '

c. P4: tu-a-tóóttéélé $X \rightarrow$ tu-a-tó'ótééle 'we thanked $\mathrm{X}$ '

In (14a) without a MH the only $\mathrm{H}$ in the form is that on the initial part of $\mathrm{P} 3$, which shifts its tone to the following syllable to avoid a rise in the first syllable. We see this illustrated in figure 1 , where we see a level $\mathrm{H}$ on the second syllable followed by a fall to low. The difference between the $\mathrm{H}$ of the syllable $-l o o-(187 \mathrm{~Hz})$ and the following low on -lwee- $(112 \mathrm{~Hz})$ is $75 \mathrm{~Hz}$ and with the initial low of twaa- $(146 \mathrm{~Hz})$ is $41 \mathrm{~Hz}$. These are both on the higher end of the range of difference between $\mathrm{H}$ and $\mathrm{L}$ as manifested in minimal pairs contrasting $\mathrm{H}$ and $\mathrm{L}$, which are typically between $25-$ $50 \mathrm{~Hz} .{ }^{16}$ This is suggestive of a raised $\mathrm{H}$. The pitch track in figure 1 is consistent with the absence of downstep because we see a gradual fall to low rather than a sharper fall with a smaller difference in pitch. Pitch tracks are generated using Praat (Boersma \& Weenink, 2014). The same speaker is used for all examples.

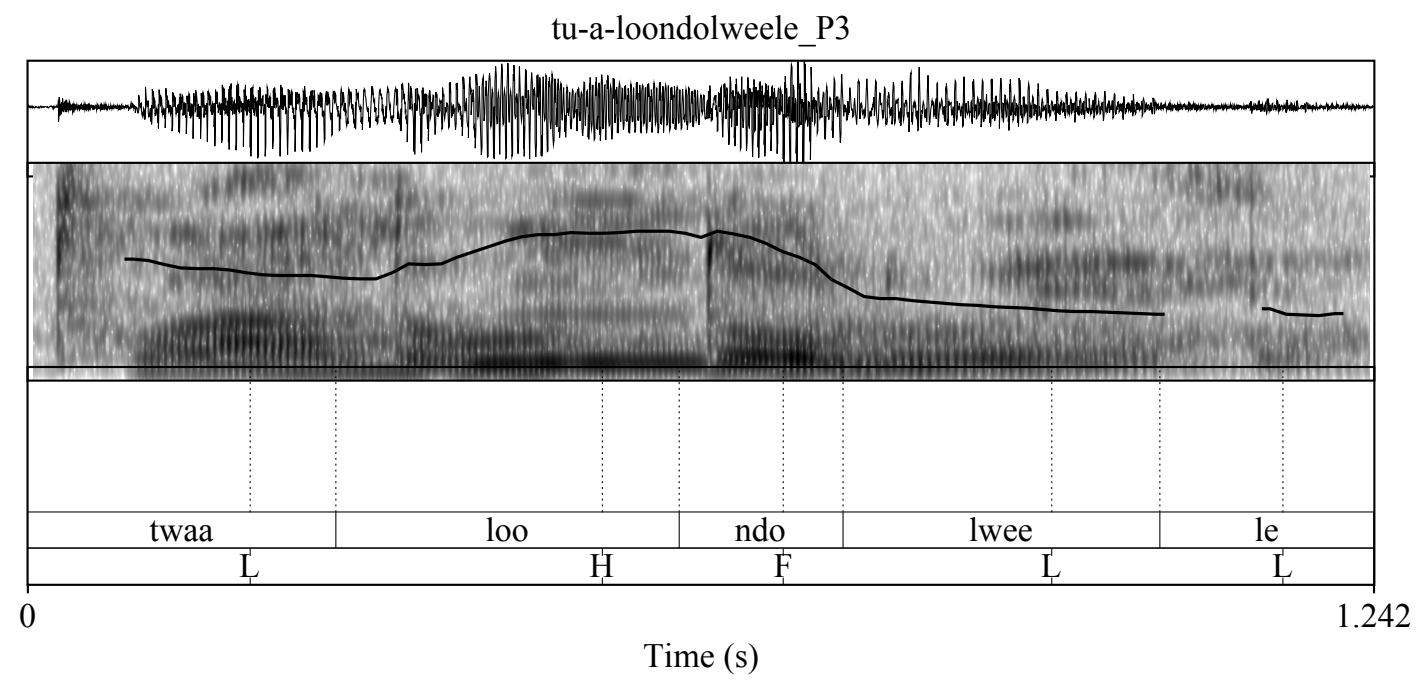

Figure 1: Pitch track of a female speaker showing a 50-250Hz range

Figure 2 illustrating the pitch track for (14b) with a H-toned verb shows the same pitch structure for P3, suggesting the absence of a V2-FV MH and possibly a raised $\mathrm{H}$. In this case the difference between the initial low $(144 \mathrm{~Hz})$ and the following $\mathrm{H}$ $(210 \mathrm{~Hz})$ is $66 \mathrm{~Hz}$ and with the following low $(112 \mathrm{~Hz})$ is over $100 \mathrm{~Hz}$, which is extremely high. This is consistent with a raised $\mathrm{H}$ and indicates a fall on the last two moras that would be unexpected if the V2-FV MH was present.

\footnotetext{
${ }^{16}$ Tone in Bantu is relative so that high tone will be produced at different pitch depending on the context of occurrence. Nevertheless, one can identify significant differences in pitch that lead to the perception of low or high tone. See Kula \& Braun (2015) for some discussion of the perception of tone in Bemba.
} 
tu-a-tooteele P3

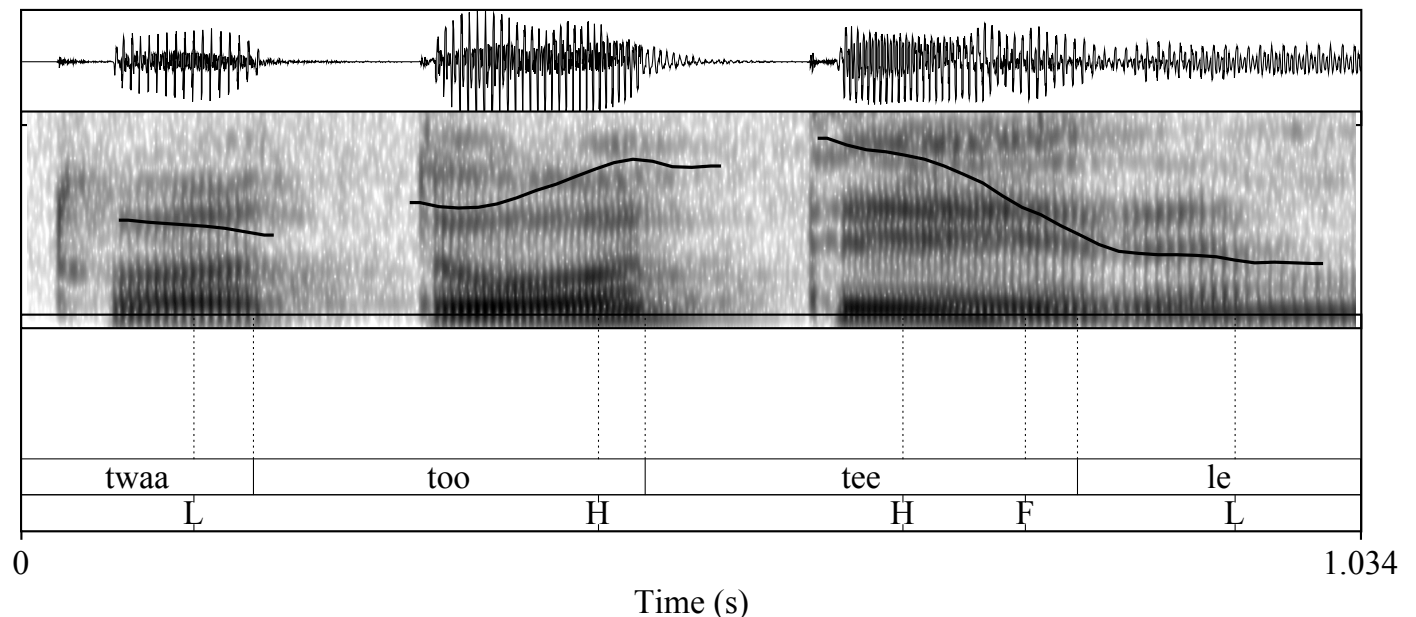

Figure 2: Pitch track of a female speaker showing a 50-250Hz range

By contrast, the pitch track for $\mathrm{P} 4$, with a H-toned verb in figure 3, is more suggestive of downstep. In this particular example, the drop in pitch in the second syllable is quite small but is clearly discernible from the figure, after which a level $\mathrm{H}$ is retained. The low in the first syllable starts at $127 \mathrm{~Hz}$, the $\mathrm{H}$ is at $143 \mathrm{~Hz}$ and the following downstepped $\mathrm{H}$ is at $136 \mathrm{~Hz}$. Although the differences in hertz here seem quite minimal, they are perceivable in speech, with experimental work showing that speakers can perceive these differences (see Kula \& Braun 2015).

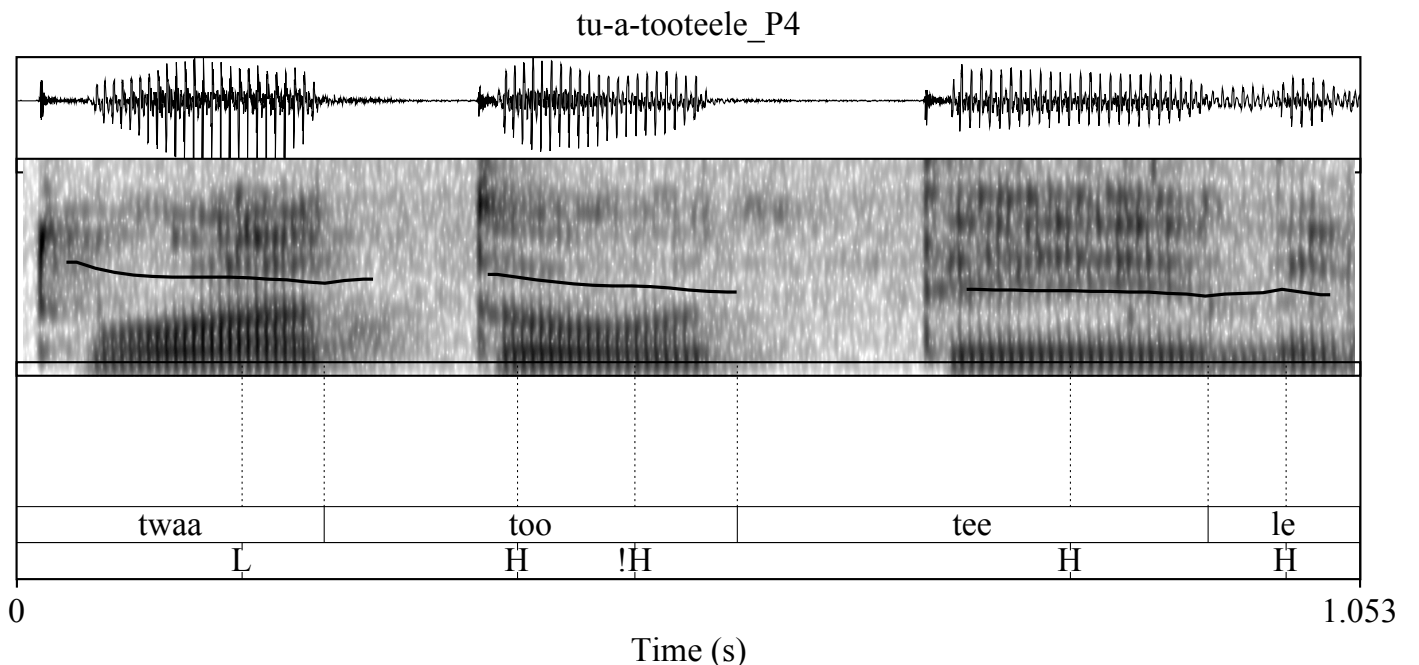

Figure 3: Pitch track of a female speaker showing a 50-250Hz range

If we follow the assumption that $\mathrm{P} 3$ did not have a $\mathrm{MH}$ associated to it at an earlier stage, but perhaps rather had a raised $\mathrm{H}$, then we can understand how the P3 and P4 forms were more distinct at that stage. ${ }^{17}$ This reasoning is supported by Meeussen's

\footnotetext{
${ }^{17}$ Given the rather, on average, significantly higher $\mathrm{H}$ on the root in $\mathrm{P} 3$, a tempting alternative hypothesis could be that $\mathrm{P} 3$ was indeed associated with a $\mathrm{MH}$, but rather than target V2-FV it targeted the root instead. This then enhanced already $\mathrm{H}$-toned verbs via $\mathrm{H}$ fusion. The current change resulting in the merger of P3 and P4 would then involve a shift of the root associated $\mathrm{MH}$ to the right in which case it gets associated to $\mathrm{V} 2-\mathrm{FV}$ as in P4, perhaps by analogy. There is no precedence of MHs that target roots in Bantu, since it is assumed these are lexically specified for tone, but there is ample
} 
(1967: 113) tentative (his evaluation) reconstruction of past tense forms where he distinguishes two forms with the -ile (*ide) ending which contrast with respect to the presence/absence of high tone as in (15) below.

(15) Meeussen's (1967) PB past forms reconstructions

(a) *a- -a recent imperfective

(b) *á- -a preterite imperfective

(c) *a- -ídé recent perfective

(d) *á- -ide preterite perfective

From the semantics P3 corresponds closest to (15c) and P4 to (15d), although the tones have the opposite correspondences. What is crucial is that the two forms in $(15 \mathrm{c}-\mathrm{d})$ are distinguished by contrasting tone both on the initial and final. This bodes well with the idea that $\mathrm{P} 3$ in Bemba did not historically have a $\mathrm{MH}$, on a par with the form in (15d). In fact, examination of Sharman's (1956) NB data shows that he contrasts P3 and P4 with only P4, but not P3, associated with 'post-radical Highs' (equivalent to the V2-FV MH). From this perspective then, the current situation could have been instigated by the loss of the raised $\mathrm{H}$ (if it was present) and introduction of a $\mathrm{MH}$ into the $\mathrm{P} 3$ forms, on analogy with $\mathrm{P} 4$, which then resulted in the observed tonal neutralization effects (discussed in 3.1.1), that then led to a loss of distinction between $\mathrm{P} 3$ and $\mathrm{P} 4$.

It is clear from this discussion that there are good reasons for arguing that phonological factors have played a role in the merger of P3 and P4. Treating neutralization as stemming from an introduction of a $\mathrm{MH}$ in $\mathrm{P} 3$, extends the process to a wider range of contexts that is more likely to enhance a global change. The next section considers morphological form as another possible contributing factor to the merger.

\subsection{Morphological form}

As already noted above P3 and P4 are in terms of morphological form almost identical, with both having an initial - $a$ - and -ile ending, with only a difference in the tone of the initial. This holds for the conjoint but not the disjoint forms which have distinct endings as shown in (16) below. The initial parts of the P3-P4 disjoint forms are more similar, with only a difference in length between the two forms, in addition to tonal contrasts.

(16) Morphological forms of the Past (P1-P4)

\begin{tabular}{|c|c|c|}
\hline TENSE & CONJOINT & DISJOINT \\
\hline $\mathrm{P} 1$ & $-a-\quad-a$ & -áa- -a \\
\hline $\mathrm{P} 2$ & -ácí- -a & -ácí- -a \\
\hline P3 & -á- -ile & -álii- -a \\
\hline P4 & -ile & -alí- -ile \\
\hline
\end{tabular}

An attempt is made here to break down the morphemes involved into their component parts, with possible associated independent meanings that might explain

discussion of floating tones, in which case this would be one associated with P3. There is no evidence in synchronic Bemba tonology to suggested that $\mathrm{H}$ fusion results in higher pitched $\mathrm{Hs}$, although no study has been conducted. 
the different past tense forms. Nurse (2008) notes that the formative $-a$ - is the most widely used in Bantu TAM systems. In the past tense this formative is used with past distinctions contrasted with different tones and length of $-a-$. We see the $-a-$ associated to past events appearing in the initial part of all the forms P1 to P4, so that every past event must be denoted either in whole or in part by an initial $-a-$. The final part of the past tense marking indicates how far back in the past the event is. Final -a refers to those events that hold in the current time. This feature unifies P1 and P2 as pasts of today. The aspectual marker -ci-, in the initial part of $\mathrm{P} 2$, denotes the event as holding at any point within a longer period (here within today; hodiernal) and thus refers to a longer time region with respect to the speech event, in contrast to $\mathrm{P} 1$. We can, for example, see the contribution of aspectual -ci- when it is used in combination with - $l i$ - (a copular verb derived from the verb 'to be') and which aspectually denotes a current ongoing event, leading to a persistive meaning; an on-going event. We see, for example, the persistive marked by -ci-li- in (17a-b).
a. bá-cíli ku-nganda
2SM-PERSISTIVE 17-house
'They are still at home"
b. bá-cíli-bá-lée-ly-a
2SM-PERSISTIVE-2SM-PROG-eat-FV
'They are still eating'

Thus the morphological forms of $\mathrm{P} 1$ and $\mathrm{P} 2$ can be distinguished as referring to shorter (P1) and longer (P2) time regions within 'today'. P3 and P4 both have the ending -ile which reflects the perfective aspect in many Bantu languages as in Bemba (Nurse 2008). The combination of the marker $-a$ - for past and -ile for perfective then gives us perfective past meanings which are then used to refer to pasts of the hesternal and beyond. The distinction between a hesternal past (P3) and a more distal past (P4) is marked by a difference in tone, $\mathrm{H}$ for P3 and low for P4. In Bemba this is extended to also refer to events that occurred some days before yesterday and which are still relevant to the current speech event. Thus, both the conjoint and disjoint forms of P3 have a $\mathrm{H}$-toned initial - $\dot{a}$-. There certainly is no reason to believe that tone is less stable than segmental material, indeed its autosegmental nature attests to its stability (Goldsmith 1979). However, with the preceding discussion showing that the $\mathrm{H}$ tone denoting P3 is oft times shifted to avoid a rising tone pattern, this could lead to the loss of the $\mathrm{H}$ on the initial $-a$ - making it compositionally identical to $\mathrm{P} 4$. This would then lead to the merger rendering P3 and P4 identical in terms of morphological form based on associated function. Namely, if the initial - $a$ - of P3 loses its tone then it no longer denotes a restricted domain associated to the hesternal past, but has wider scope as $\mathrm{P} 4$ does.

The disjoint P3 and P4 forms, as noted above, capture a difference in time depth by distinguishing initial $-a$ - tonally. They share the aspectual marker -li-, already discussed above as derived from a copular. Their endings distinguish them further with P3 having the final $-a$ of $\mathrm{P} 1$ and P2 that we described as referring to events that hold in the current time. In the case of P3 'current time' refers to the continued perceived relevance of the past action of the verb, in contrast to $\mathrm{P} 4$ with -ile ending. ${ }^{18}$

\footnotetext{
${ }^{18}$ Consider a scenario with respect to eating maize that was presented to speakers. Disjoint P3 (tu-aliilya; 1PL-P3-eat) was used in those hesternal cases where the cobs were still in the bin, for example.
} 
I cannot find any particular import of the lengthened vowel of -li- in P3 nor of the $\mathrm{H}$ in the -li- form of P4 and treat these as of phonological rather than of morphological consequence.

An explanation based on form similarity implies that we expect, or are more likely to see a merger, in the conjoint rather than the disjoint forms. This is indeed borne out in that, in contrast to the conjoint forms, the two disjoint forms remain in use, albeit with changes to their semantic coverage. We return to a discussion of disjoint forms in section 3.5. Reasoning based on form, leaves the question why P3, rather than P4, is lost, or alternatively, why the merger is in the direction of P4 rather than P3. We try to address this particular issue by looking at the role that semantics may have played in the current loss of $\mathrm{P} 3$, in the following section.

\subsection{Semantic function}

A central issue in this discussion is what is happening to the function of $\mathrm{P} 3$ when it is lost. Does the loss of P3 imply that speakers are no longer able to express the specific timespan that is the reference of P3? Seen from a timeline point of view the division of P1 to P4 prior to the loss of P3 can be depicted as in (18) below, starting from time 'now' (utterance time on the right edge) moving backwards in time. The divisions shows P3 as referring to time beyond yesterday to include the day before yesterday and a few days before that. P4 on the other hand, refers to all events preceding P3.

(18) Previous use of P3 in both NB and CB

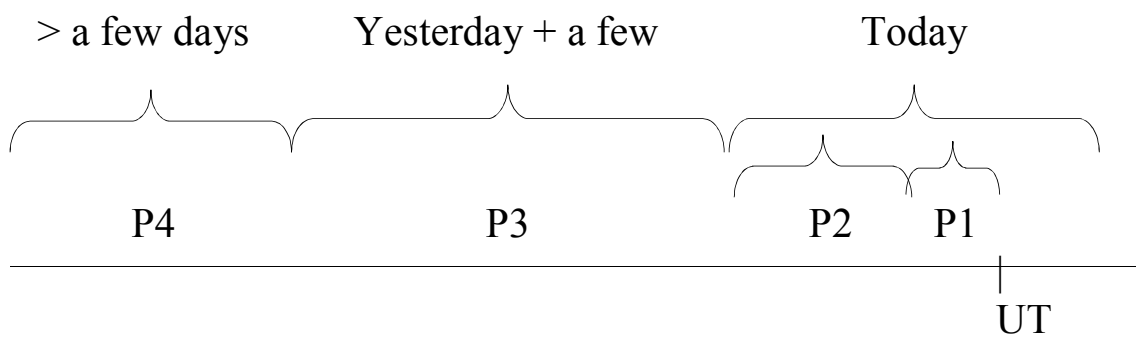

Let us consider some examples below that have been used to argue for a construal of the division of time as depicted in (18).

(19) Previous noted use of P1-P4

a. Chisanga a-a-lyá nombaline

Chisanga 1SM-P1-eat just.now

'Chisanga has just eaten'

b. Chisanga a-ácí-lyá uluceelo

Chisanga 1SM-P2-eat in.the.morning

'Chisanga ate in the morning'

c. Chisanga a-a-líilè mailo/bulya bushiku

Chisanga 1SM-P3-eat yesterday/day before yesterday

'Chisanga ate yesterday/day before yesterday'

Whereas P4 (tu-alí-liile) was used in reference to an event that occurred at a point in a past time but for which we can currently see no evidence of the eating activity. 
d. Chisanga a-a-líilé ulya mwaka/kale (*mailo/bulya bushiku)

Chisanga 1SM-P4-eat that year (=year before last)/long.time.ago

'Chisanga ate the year before last/ a long time ago'

If these are the timeline divisions for $\mathrm{P} 3$ and $\mathrm{P} 4$, then the prediction is that, if $\mathrm{P} 3$ is maintained in the system, P4 in (19d) should not be used with reference to 'yesterday' or 'day before yesterday'. These should be reserved for P3. The current use, however, shows that P4 is used in these contexts, with no separate independent P3 context use. In this sense, P4 covers all past events beyond and including the hesternal, as depicted in (20). Illustrative examples, using the same verb as above in (19), are given in (21).

(20) Current use both in NB and CB shows:

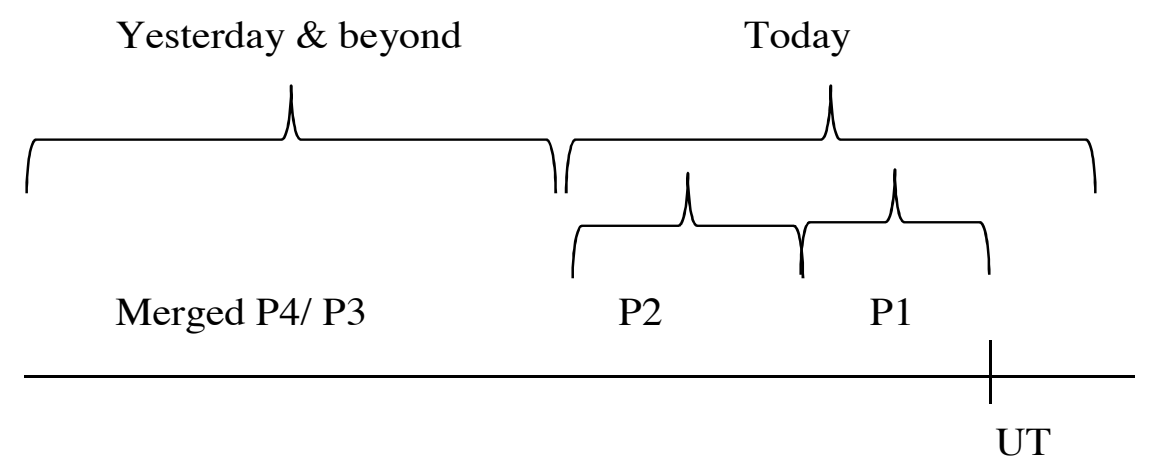

(21) Current use of P1-P4 with P4 including P3 contexts

a. P1: Chisanga a-a-lyá nombaline/ uluceelo /*mailo (+ beyond)

Chisanga 1SM-P1-eat just.now/ in.the.morning/*yesterday

b. P2: Chisanga a-ácí-lyá nombaline / uluceelo /*mailo (+ beyond)

Chisanga 1SM-P2-eat just.now /in.the.morning/*yesterday

c. P3: *Chisanga a-a-líílè mailo /bulya bushiku

Chisanga 1SM-P3-eat yesterday/day.before.yesterday

d. P4: Chisanga a-a-líilé mailo /bulya bushiku /uyu mwaka/kale

Chisanga 1SM-P4-eat yesterday/day.before.ystrdy /last year /long.ago

As (21d) shows all events occurring yesterday or beyond are referred to using P4 and there is no longer a specific marking referring to 'yesterday $+a$ few days beyond yesterday', at least in the conjoint form. Note though, in addition, that in (21a-b) we see that P1 can be used in P2 contexts and vice versa, depending on the context. It is worth probing this a little further, in order to test whether there are contexts where one past form can be extended to past contexts of another, i.e. to check possible exclusive and inclusive interpretations. This will help us to better delineate the scope of each past tense form. We will discuss the possibility of each past to be extended to 
the contexts of the other pasts in the following examples. Conjoint forms are used, apart from P3 where the disjoint form -álii $-a$ is used. ${ }^{19}$

(22) P1 scenario

a. a-ba-kashana ba-a-fik-a na baasi ba-fwiile uku-ya-imb-a AUG-2-girl 2SM-P1-arrive-FV with 9bus 2SM-should 15-go-sing-FV 'The girls who have just arrived by bus have to go and sing'

b. Chisanga elyo a-a-fik-a fye/ a-aci-fika ulu-ceelo/

Chisanga COP 1SM-P1-arrive-FV just/ 1SM-P2-arrive-FV 11-morning/

a-alii-fik-a/ a-a-fik-ile uyu mwaka.

1SM-P3-arrive-fv 1SM-P4-arrive-PERF last 3year

Bushe na-o a-fwiile uku-ya-imb-a-ko?

Q and-RCD 1SM-should 15-go-sing-FV

'Chisanga arrived at P1/P2/P3/P4. Should he also go and sing?'

Answers to entailments: P1:Yes; P2: Yes; P3: No; P4:No

(22) shows that when P1 is used, reference can also be made to P2 but not to P3 and $\mathrm{P} 4$. The responses were not unanimous in the data with respect to P1 scoping over $\mathrm{P} 2$, with some subjects only allowing P1 in some examples. Subjects were, however, agreed on disallowing $\mathrm{P} 3$ and $\mathrm{P} 4$ contexts from being entailed from $\mathrm{P} 1$ and $\mathrm{P} 2$.

(23) P2 scenario

a. Mutale nga-a-aci-shit-a ifyakulya ninshi tu-alaa-y-a

Mutale COMPL-1SM-P2-buy-FV 8 food then 2PL-F1-go-FV

mu-ku-ow-a

18LOC-15-swim-FV

'If Mutale bought the food (at P2) then we will go and swim'

b. Mutale elyo a-a-shit-a ifyakula nombaline fye/ a-aci-shit-a

Mutale COP 1SM-P1-buy-FV 8 food just.now just/ 1SM-P2-buy-FV

uluceelo / a-alii-shit-a bulya bushiku/a-a-shit-ile uyu

11 morning 1SM-P3-buy-FV 14DEM4 14day 1SM-P4-buy-PERF 3DEM1

mweshi. Bushe tu-alaa-y-a mu-ku-ow-a?

3month Q 1PL-F1-go-FV 18LOC-15-swim-FV

'Mutale bought (the) food at P1/P2/P3/P4. Are we going to go and swim?'

\footnotetext{
${ }^{19}$ Thanks to Mary Dalrymple with whom these scope examples have been developed and discussed. These data were collected from 9 speakers using a questionnaire that set out a scenario in one of the pasts and provided a set of entailments in different pasts, based on a scenario. Thes were then judged as true or false as presented here. Similar data were collected for the future. In addition to declarative contexts, negation, question, conditional and quantified contexts were also tested. Since tone is not marked in orthography, the questionnaire and the results reported here are only based on forms that could unambiguously be identified as the intended past or future. Adverbs were used in all cases to support the intended reading.
} 
Similarly for P2 in example (23), P2 can scope downwards to P1 but not upwards to P3 and P4. Again subjects showed variation in particular examples where P2 was not allowed to scope over P1. P3 and P4 were excluded.

(24) P3 scenario

a. Bupe nga-a-alii-fik-a ninshi a-li ku-nganda

Bupe COMPL-1SM-P3-arrive-FV then 1SM-be 17LOC-9house

'If Bupe arrived at P3 then he is at home'

b. Bupe elyo a-a-fik-a fye/ a-aci-fik-a leelo/

Bupe COP 1SM-P1-arrive-FV just 1SM-P2-arrive-FV today

a-alii-fik-a mailo / a-a-fik-ile uyu mulungu.

1SM-P3-arrive-FV yesterday 1SM-P4-arrive-PERF 3DEM2 3week

Bushe a-li ku-nganda?

Q 1SM-be 15-9house

'Bupe arrived at $\mathrm{P} 1 / \mathrm{P} 2 / \mathrm{P} 3 / \mathrm{P} 4$. Is he at home?'

Answers to entailments: P1: No; P2:No; P3: Yes; P4: Yes

In (24) we use the disjoint form of P3 as a way of understanding the lost P3 conjoint form. The assumption is that the P3 conjoint form would have likely patterned in the same way, if extent of remoteness is the main feature distinguishing interpretations in these examples. For P3 we see that scope can extend towards P4 but not to $\mathrm{P} 1$ and $\mathrm{P} 2$. There was no variation with respect to $\mathrm{P} 3$ and $\mathrm{P} 4$, with results generally distinguishing the hodiernal and hesternal pasts.

(25) P4 scenario

a. Kabwe ta-a-a-ile ku-mafundisho

Kabwe NEG-1SM-P4-go-PERF 17LOC-6instruction

'Kabwe did not go to the instructions at P4'

b. Bushe ifi ba-sos-a ci-shinka nga cakuti Kabwe elyo Q 8DEM1 2SM-say-FV7-true if is.the.case.that Kabwe COP

$\begin{aligned} & \text { a-a-ya-a / a-aci-y-a } \\ & \text { 1SM-P1-go-FV / }\end{aligned}$ 1SM-P2-go-FV 11 morning / 1 SM-P3-go-FV/
a-a-ile
1SM-P4-go.PERF $\quad$ 3DEM1 3month 17LOC-6instructions
'Is the above statement true if Kabwe went to the instructions at P1/P2/P3/P4?'

Answers to entailments: P1:Yes; P2: Yes; P3: No; P4:No

Finally, (25) for P4 shows the same pattern as P3. Here a negative context is used. $\mathrm{P} 1$ and $\mathrm{P} 2$ are deemed as not falsifying a statement made about a P4 context and thus 
show their exclusivity from P4. P3 on the other hand falsifies the statement in (25a), showing that $\mathrm{P} 4$ can be used to refer to $\mathrm{P} 3$ contexts.

This distribution of data shows that there is some flexibility in the reference of the four pasts, showing that while there seems to be a demarcation between P1/P2 vs. $\mathrm{P} 3 / \mathrm{P} 4$, there is no crisp distinction between $\mathrm{P} 1$ and $\mathrm{P} 2$, on the one hand, and $\mathrm{P} 3$ and $\mathrm{P} 4$, on the other. This contrasts with what might be expected from a linear timeline view. Importantly, for the loss of P3 in the conjoint form, this provides additional argumentation for why P3 merges with P4, rather than P2 with which it is equally adjacent on a linear timeline.

\section{$3.4 \quad$ Paradigm uniformity}

So far we have looked at the past tense outside of the whole tense system of Bemba of which it is a part. The loss of P3 may be additionally motivated by other factors to do with the general organisation of the tense system. Although work on Bantu languages is generally biased towards a morpheme-based approach to morphology, due to the agglutinative nature of morphology, there may be some insight to be gained from looking at Bantu tense systems more from a paradigm-based morphology perspective. The latter perspective is pursued in, for example, the work of Corbett \& Fraser (1993), Spencer (2013), Stump (2001), among others. Paradigm-based morphology, which is most utilized to account for languages with inflectional classes, allows morphological systems to be analysed in terms of default inheritance, where properties in one part of a paradigm lend support to the analysis of another part of the paradigm. In this sense, morphological forms are said to create networks or relations as, for example, argued in the Network Morphology approach of Corbett \& Fraser (1993).

If we draw from this general insight, which has been used to explain the organisation of a cross-linguistic set of inflectional systems, we can consider the reduction seen in the past tense (conjoint) paradigm, as resulting in better alignment of the past with the future forms. As noted earlier, there are three futures whose distribution mirrors the P1/P2 and P3/P4 split, as shown in (26) below. The future only has one form to capture the mirror image contexts of $\mathrm{P} 3 / \mathrm{P} 4$, i.e. the future after today is expressed by F3. F1 expresses an immediate future and F2 a future within today. The loss of P3 within this representation results in a parallel distribution between the pasts and the futures, at least for the conjoint forms. In this sense paradigm uniformity may be another motivating factor, or at least a compatible outcome in the loss of P3. ${ }^{20}$

\footnotetext{
${ }^{20}$ This outcome, however, as a reviewer points out, overrides the typologically less marked distribution where past categories cross-linguistically outnumber future categories. We can make two observations in this respect. The first is that the uniformity argument currently only holds in the conjoint forms but is less obvious in the disjoint forms, at least in terms of number of formatives, meaning that more globally the past is still more complex than the future. This follows from the fact that the future has no conjoint-disjoint alternation. The second is that perhaps paradigm uniformity may only be a transitory illusion with convergence then expected in the future forms at a later point in time to redeem the unmarked relation between pasts and futures. In any case, future research will have to consider what pragmatic triggers may lead to paradigm uniformity in order to strengthen this argument.
} 
(26) Bemba Past and Future simple tenses compared

\begin{tabular}{|c|c|c|c|c|}
\hline TENSE & $\mathrm{CONJ}$ & DISJ & & $\mathrm{CONJ} / \mathrm{DISJ}$ \\
\hline P1 & -á--a & -áa- -a & F1 & -áláa--a \\
\hline $\mathrm{P} 2$ & \multicolumn{2}{|c|}{-ácí- -a } & F2 & -lée- -a/-lee- -a \\
\hline $\mathrm{P} 3$ & -á--ile & -álii- -a & \multirow{2}{*}{ F3 } & \multirow{2}{*}{$-k a-\quad-a$} \\
\hline P4 & -a--ile & -alí- -ile & & \\
\hline
\end{tabular}

(27) Bemba Future contrasts

F1: immediate future/just now/within today (parallel to P1)

F2: future within today (and contextual use denoting high relevance to the present) (parallel to $\mathrm{P} 2$ )

F3: future after today including tomorrow and the distant future (this function parallels a combination of $\mathrm{P} 3$ and $\mathrm{P} 4$ functions)

As we noted with the pasts in section 3.3 above, the future also shows similar entailment patterns, with F1 able to extend to include F2 and vice versa. By contrast, F3 does not extend to F1 or F2 contexts. Consider the examples below in this respect.

(28) F1 scenario

a. abaleendo a-ba-alaa-fik-a ba-ka-y-a ku-mumana 2traveller 2AUG.REL-2SM-F1-arrve-FV 2SM-F3-go-FV 17LOC-river 'The travellers who will arrive (at F1) will go to the river'

b. Bamayo ba-laa-fika nombaline / ba-lee-fik-a akasuba/ 2mother 2SM-F1-arrive-FV just.now / 2SM-F2-arrive-FV afternoon

ba-ka-fik-a mailo. Bushe na-bo ba-ka-y-a ku-mumana? 2SM-F3-arrive-FV tomorrow $\mathrm{Q}$ and-2RCD 2SM-F3-go-FV 17LOC-river 'Mother will arrive at F1/F2/F3. Will she also go to the river?'

Answers to entailments: F1: Yes; F2: Yes; F3: No

(29) F2 scenario

a. Bushe Kabwe a-lee-fik-a

Q Kabwe 1SM-F2-arrive-FV

'Will Kabwe arrive (at F2)?'

b. Kabwe a-alaa-fik-a nombaline / a-lee-fik-a icungulo / Kabwe 1SM-F1-arrive-FV just.now/ 1SM-F2-arrive-FV evening /

a-ka-fik-a mailo. Mu-alaa-asuk-a shaani ilipusho? 1SM-F3-arrive-FV tomorrow 2PL-F1-answer-FV how 5quection 'Kabwe will arrive at F1/F2/F3. How can you answer the question (in 29a)?'

Answers to entailments: F1: Yes; F2: Yes; F3: No 
In (28-29) there was unanimous response allowing F1 to take scope over F2 and likewise, F2 over F1 to the exclusion of F3. These examples thus show a split between $\mathrm{F} 1 / \mathrm{F} 2$, on the one hand, and F3, on the other.

(30) F3 scenario

a. Nga-a-ka-sangw-a-ko Mutale ku-masambililo ninshi COMPL-1SM-F3-be.present-FV-17LOC Mutale 17LOC-6study then

a-lee-ya-lemb-esh-a leelo

1SM-F2-go-write-CAUS-FV today

'If Mutale has the intention of being at the instructions at F3 then he will go and register today'

b. Mutale a-alaa-b-a ku-masambililo nombaline / a-lee-b-a Mutale 1SM-F1-be-FV 17LOC-6study just.now / 1SM-F2-be-FV

$\begin{array}{lllll}\text { ku-masambililo } & \text { leelo / } & \text { a-ka-b-a } & \text { ku-masambililo } & \text { uyu mweshi. } \\ \text { 17LOC-study } & \text { today/ } & \text { 1SM-F3-be-FV } & \text { 17LOC-6study } & \text { 3DEM1 3month }\end{array}$

Bushe a-lee-ya-lemb-esh-a?

Q 1SM-F2-go-write-CAUSE-FV

'Mutale will be at the instructions at F1/F2/F3. Will he go at register?'

Answers to entailments: F1: No; F2: No; F3: Yes

For F3 in (30), a couple of speakers allowed F3 to take scope over both F1 and F2. Discussion with these subjects revealed that they had treated the event globally with no real attention paid to the future form used but rather judged taking part in the studies/instructions as requiring registration, irrespective of when this would be. A number of speakers treated the 'then' clause of the conditional in (30a) not as a future form, but as a subjunctive, as in 'should go and register'. This suggests that the F2 future marker -lee- and the verb 'go' have grammaticalised into a subjunctive meaning. ${ }^{21}$ This has no impact on the point at hand as the target future form was in the initial part of the conditional. The examples thus support an interpretation of F3 that excludes F1 and F2.

Apart from these scope possibilities, the future also usually incorporates modality with respect to certainty, where F1 and F2 denote events that are more certain to occur in contrast to F3.

We can thus conclude that given the distribution of the future, the loss of P3 would result in a parallel alignment between the pasts and futures, assuming that speakers processing of tense is in some way influenced by the structure of the whole paradigm, as paradigm-based approaches to morphology suggest. In this sense, system pressure would be another factor leading to the loss of P3, achieved by the merger of P3 and P4.

\footnotetext{
${ }^{21}$ There is also probably some interaction with the fact that -lee- is also the marker of a present progressive. See Devos \& van der Wal (2014) and references therein, for some discussion of different grammaticalizations of go in Bantu.
} 
Our focus has thus far mainly been on the conjoint forms, where the merger under discussion is apparent. Let us now briefly consider the disjoint forms and evaluate to what extent $\mathrm{P} 3$ remains active in this part of the paradigm.

\subsection{P3 and P4 in Disjoint forms}

Recall the forms of the disjoint form presented earlier as -álii- $-a$, for the P3 disjoint form, and -ali- -ile, for the P4 disjoint form. In terms of form they both contain the initial $-a$-denoting past, with the $\mathrm{P} 3$ form having a $\mathrm{H}$ on this $-a$ - as in the conjoint forms. Both forms also have -li- in the initial part which is derived from the verb 'to be'. The P3 form has a lengthened vowel in -li- to further distinguish the forms. The two forms are further distinguished by their finals, with P3 having the neutral $-a$ final while P4 has -ile. The disjoint forms differ in this respect from the conjoint forms, which both use -ile. Thus, based purely on form, there are no grounds on which to anticipate merger between P3 and P4 in the disjoint forms. Similarly, despite the fact that they have different tonal patterns, without the requisite identical form, there is no possibility of tonal neutralization. On the other hand the arguments of paradigm uniformity remain and as was illustrated earlier the $\mathrm{P} 3$ disjoint form has the flexibility to scope over P4 contexts. There are, in addition, further changes going on in the disjoint forms in terms of function and semantics resulting in a reconfiguration of the system that we now investigate in more detail. ${ }^{22}$

Consider, to begin with, the examples in (31) that illustrate the supposed previous use of the disjoint P3/P4 forms, as presented in the literature (Hoch 1963, Sharman \& Meeussen 1955, van Sambeek 1955). The superscript arrow in P3 indicates the raised $\mathrm{H}$ that was originally associated to P3 in Sharman \& Meeussen.
a. P3: Chisanga a- $\underline{a}^{\uparrow} l$ lí́-yà (mailo/bulya bushiku/*kale)
Chisanga 1SM-P3-go (yesterday/ day before yesterday/*long ago)
'Chisanga went yesterday/day before yesterday/*long ago'
b. P4: Chisanga a-alí-1ílé (ulya mwaka/kale/*mailo/*bulya bushiku)
Chisanga 1SM-P4-go (year before last/long. ago/*yesterday/
*day.before.yesterday)
'Chisanga went (to some place), last year/a long time ago'

These uses distinguish P3 and P4 as used to refer to a past of yesterday + a few days before for P3 vs. a past beyond that and particularly the remote past for P4. Note that in $\mathrm{P} 3$ the $\mathrm{H}$ of the initial -a-, in the past tense marker, shifts its tone to the next syllable to avoid a rise, a process we have discussed earlier. The resultant $\mathrm{H}$ of -liihas the same raised $\mathrm{H}$ characteristics of the lost $\mathrm{P} 3$ conjoint form, illustrated in the pitch tracks in figures (1-2). If we entertain the hypothesis of a raised $\mathrm{H}$, then we can unify the conjoint and disjoint $\mathrm{P} 3$ forms as both having a raised $\mathrm{H}$ targeting the initial verb, be it lexical or auxiliary. This suggests that the raised $\mathrm{H}$ was present in the language at a time when the -li- of the disjoint P3 marker still had auxiliary verb status. In terms of tone, this form in (31a) is now, akin to the P3 conjoint form, not

\footnotetext{
${ }^{22}$ It should be clear that while P3 is completely obsolete in current usage in the conjoint form, with both its restricted meaning and form lost, it is tentatively present in the disjoint form, with the distinct P3 formative still present but with shifting semantics allowing it to also be used in P4 contexts, as the examples in (32) and accompanying discussion will illustrate. It is suggested that this current flexible scope, as well as the accompanying tonal changes, attest to its erosion and possible loss in the future as a singular marker of $\mathrm{P} 3$ contexts.
} 
actively used, although when presented it is recognized by some speakers (mainly older speakers). In this case the tonal pattern is lost and neutralized to a regular $\mathrm{H}$ tone as in (32a). As we noted earlier the P3 disjoint form can take scope over P4 contexts and vice-versa, but not over P1 and P2, i.e. this holds in the disjoint paradigm as well. Consider the current use of the disjoint P3 and P4 forms in (32) below.
a. P3: Chisanga a-alíí-yà (mailo/bulya bushiku/uyu mwaka/akale) ${ }^{23}$
Chisanga 1SM-P3-go (yesterday/day before yesterday/last year/long.ago)
'Chisanga went yesterday/day before yesterday/last year/ a long time ago'
b. P4: Chisanga a-alí-1ílé (mailo/bulya bushiku/ulya mwaka/kale)
Chisanga 1SM-P4-go (yesterday/day.before.yesterday/ year.before.last/long.ago)

'Chisanga went yesterday/day before yesterday/year before last year/a long time ago'

Note the parallel contexts of use for P3 and P4 in (32). There is however some implied aspectual interpretation, where P3 is most usually used in contexts where the person who has left is still gone. By contrast, $\mathrm{P} 4$ allows the possibility that the person may have returned. Perhaps this is the retained subtle difference between P3 and P4, where the effects of the action at P3 are present at the time of the speech event but not at P4. This, though, results in some redundancy in the TAM system since there is an anterior (also referred to as perfect) remote past form which combines the P4 initial with an $-a$ ending (-ali- $-a)$, marking an event in the past whose truth value still holds at the current time (see Appendix A). This is illustrated in (33a). The counterpart conjoint (anterior P4) form marked by $(-a--a)$ is given in (33b).
a. Chisanga a-alí-y-á (kale/*mailo/*bulya bushiku/*uyu mwaka) DJ Chisanga 1SM-P4-go-FV (long.ago/*yesterday/*day before yesterday/ *last year)
'Chisanga has/is gone (a long time ago/*yesterday/*day before yesterday/ *last year)'
b. Chisanga a-a-y-a kale (*mailo/*bulya bushiku/*uyu mwaka)CJ Chisanga 1SM-P4-go-FV long.ago(*yesterday/*day.before.yesterday/ last year)

Both (33a-b) illustrate events in the remote past that are deemed as still holding i.e. the person is still gone and could not have been gone and come back again, as (32b) allows.

Thus, in terms of function and scope, there is little difference in the current use of P3 and P4 in the disjoint form such that in this case too we may conclude that the

\footnotetext{
${ }^{23}$ The form for 'a long time ago' fluctuates between having an augment (the initial vowel) and not, thus a-kale vs. kale. It is not clear to me at this stage what this distribution is based on but in (32a), contra (32b), the use of kale (without the augment) is ungrammatical and can only be interpreted as the homonymous form 'kale' meaning 'already', which is not intended in these examples. See de Blois (1970) for some discussion of functions of the augment which vary between different Bantu languages. The tri-moraic vowels in the verb in (31b) and (32b) undergo 'mora pruning' and surface as bi-moraic long vowels.
} 
specific reference of P3 as only denoting those events that fall under 'yesterday + a few days before' has been lost, resulting in two forms that both mark P3 and P4 or, from the point of view of function, a merger of P3 and P4, as discussed for the conjoint forms. This shows that while the distinct forms are retained their functions have been collapsed, thus illustrating a reconfiguration in the disjoint part of the tense system. What we then remain with overall is 3 forms that all mark the merged function of P3 and P4; one form in the conjoint form and two forms in the disjoint form. Whether the two forms of the disjoint form which fulfil the same function will continue to be retained in the system, remains to be seen.

The situation is, in addition, further complicated by the fact that most of the function of the conjoint-disjoint alternation, rather than being carried by the different morphemes, is subsumed by phonological phrasing (Kula, to appear). Bearing witness to this is the fact that at least a number of speakers when prompted to use a P3 form in a conjoint context, would use the P3 disjoint form. This shows that actually, for most speakers, the supposed P3 'disjoint form' is used in both conjoint and disjoint contexts, with phonological phrasing capturing the contrast. This follows if a morphologically marked conjoint-disjoint alternation is lost (in favour of phonological phrasing) in this TAM, with the P3 'disjoint form' getting no designation as conjoint or disjoint. A more systematic investigation of this needs to be made in future work to firmly ascertain the distributional patterns of the P3 disjoint form.

From the foregoing discussion, we can unite the conjoint and disjoint forms in terms of function as both involving the loss of P3 by an expansion of the semantic scope of P4. Phonologically, both forms have also lost the raised $\mathrm{H}$ that was associated with P3. In terms of form, the conjoint form, owing to the homonymy between P3 and P4 (in conjunction with tonal changes), only retains one form for the redefined P4, while the disjoint retains two forms. These changes result in a parallelism between the past and future forms with both showing a three way contrast.

The foregoing discussion in sub-sections 3.1-3.5 has provided motivations for the observed merger of P3 and P4 that is resulting in the loss of a distinctly defined P3 in Bemba. The different factors - phonological and morphological form, semantic function and paradigm uniformity - are not independent of each other but are rather interrelated. Thus, the most satisfactory analysis is one that can capture the relation between these different factors, which all play a role in the loss of P3 to varying extents. The goal will therefore be to present these factors as constrained and following from a particular TAM system organisation that makes the attested changes predictable. The following crucial questions will be addressed in the proposed analysis:

(i) Why does P3 merge with P4 and not, for example, P2 with which it is also adjacent on a timeline?

(ii) Why are the phonological and morphological forms of P3 and P4 much more similar to each other than they are to those of P1 and P2?

(iii) What distinguishes $\mathrm{P} 1 / \mathrm{P} 2$ from $\mathrm{P} 3 / \mathrm{P} 4$ in terms of function?

(iv) Can the idea of paradigm uniformity be better captured, i.e. be seen to logically follow from the organisation of the tense system?

We will aim to answer these questions and present a unified analysis of all the different factors presented under a cognitive view of tense in section 4 below. 


\section{A Cognitive Approach to Tense: Multi-Dimensional VieW}

The questions raised above all seem particularly problematic under a view that tense is represented as a unidimensional timeline. Under such a view the loss of P3 need not follow any particular direction, meaning that merger with P2 should be equally possible. Similarly, the forms of the past tense markers could equally well pattern together between P2 and P3, but they do not. Faced with these kinds of distributional facts in a number of Bantu languages Botne and Kershner (2008), and Botne (2012) challenge the idea that tense is represented as a unidimensional timeline divided into regular time intervals away from the speech event. Botne \& Kershner specifically argue that a uni-dimensional timeline suggests that tense markers show no overlap in reference denotation, which as we have also seen in the examples discussed above is falsified. The examples relating to scope in (24-25) for the conjoint and the disjoint forms, for example, illustrate this point. What we noted earlier is that the use of P3/P4 can make reference to 'yesterday', as well as a more distant time frame like 'last year', showing a wider range of uses than is predicted by a linear timeline. A similar pattern was seen between P1 and P2 (examples 22-23).

In contrast to this, Botne (2012) argues for a multi-dimensional representation as central to the representation of tense, with the idea that the present moment may be viewed as moving along a stationary timeline. Or alternatively, time may be viewed as flowing past a stationary present reference time point. According to Botne \& Kershner (2008) tense markers function to situate events in one of two distinct conceptual types of domain that correlate with these two different construals of time: Ego (the conceptualizer)-moving or moving time. A central contribution of this perspective is that it provides an explanation for why temporal overlap of tenses occurs. This model has been used to explain the synchronic patterning and distribution of many tense aspect systems, particularly in Bantu (see e.g. Botne 2003, 2006; Crane 2012; Kershner 2002). The goal here is to extend this model to explain language change in a TAM system, by essentially treating temporal overlap as gradually leading to a merger that results in the loss of a previously held distinction. We begin with a brief introduction to the central tenets of this multi-dimension view (MDV henceforth) of TAM systems, with focus on those issues that are directly relevant for the development of an analysis for the Bemba facts.

\subsection{Bemba P3 loss from a multi-dimensional view}

The central relevant insight from the MDV of Botne \& Kershner (2008) for the current discussion is the idea of cognitive temporal domains or mental worlds in which events are understood to occur. From this perspective, TENSE denotes a relation between $\mathrm{S}$ (the locus of the speech event = utterance time) and a particular cognitive temporal domain, in which the event referred to at $\mathrm{S}$ occurs. This relation is construed in terms of clusivity with respect to whether the deictic centre S occurs within the time span of a cognitive temporal domain. If it does, it is referred to as the P-domain. Alternatively, the deictic centre may be external to the cognitive temporal domain, in which case it is called a D-domain or dissociated domain. In this sense, the cognitive temporal domains contrast INCLUSIVITY Vs. EXCLUSIVITY with respect to the deictic centre. This is to say they contrast two perspectives: one in which temporal relations are expressed within the current domain, and another in which relations are expressed across domains. Thus, the P-domain denotes a primary, prevailing experiential past 
and future perspective, while the D-domain denotes cognitively dissociated temporal worlds or domains. This distinction is depicted in figure 4 below.

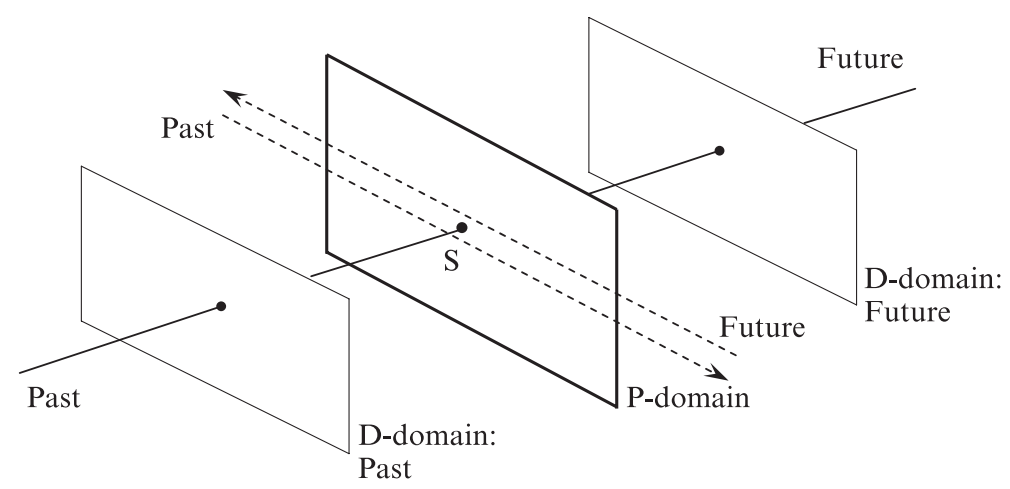

Figure 4: Cognitive worlds represented by $P$ - and D-domains

With respect to the past tense in Bemba, recall that P1 and P2 correlate with an immediate past and a past of today. These two pasts are unified by the fact that they correlate to a time which is proximate to the locus of the speech event (S) in figure 4, and show high relevance to the current time. These times are therefore best represented as inclusive of the deictic centre and therefore represented at the Pdomain. Botne and Kershner make a further distinction with respect to the organisation of events within domains and define different time regions with respect to the utterance time (UT). An event on a particular domain can be construed as either in an adjacent time region or a distal time region. The adjacent time region will be closer to the UT time while the distal time region will occur further away and after the adjacent time region. In this sense, $\mathrm{P} 1$ occurs in an adjacent time region relative to the $\mathrm{UT}$ on the P-domain, while $\mathrm{P} 2$ is a distal time region in the same domain. The time scale of $\mathrm{P} 1$ and $\mathrm{P} 2$ coincides with 24 hours matching the functional use of P1 and P2 as pasts of today. This is shown in figure 5 below where -B- stands for verbal base.

The original use of P3 and P4 was parallel to this and can be captured as representing a higher level time scale, correlating to a time span from a day and beyond. At this higher level time scale on the P-domain, P3 mirrors P1 as an adjacent time region, and $\mathrm{P} 4$ mirrors $\mathrm{P} 2$ as a distal time region. In this sense, the restricted reference of $\mathrm{P} 3$ as an adjacent time region can be understood. This is illustrated in figure 5 .

What this model also elegantly captures is the fact that adjacent and distal time regions are to be understood with respect to the UT, in the context in which this is uttered. Thus, while a linear timeline representation forces us to view 'last year' with respect to the current time as 'a long time ago', this is not necessarily the case in the current model, which locates an event with respect to its context of occurrence at utterance time. Thus, if reference is made to an event which occurs once a year, the adjacent time region will be the previous year with no relevance attached to the fact that this may have been temporally 12 months ago. In this sense, the time denoted by $\mathrm{P} 4$ varies according to context, but always denotes the relevant time unit preceding the temporal locus that is referred to. Hence, the ability to refer to yesterday, last week, last month, last year, etc. But consequently, the temporal denotation overlaps that of $\mathrm{P} 3$ in time and this is what could result in a merger, as seen, over time. 
Time scale

DAYS +

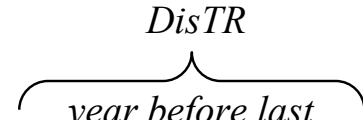

year before last month before last day before yesterday

-a-B-ile

P4

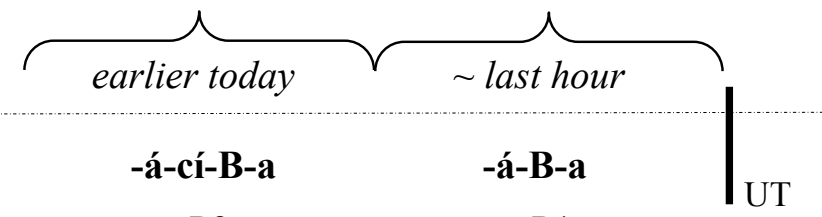

P1

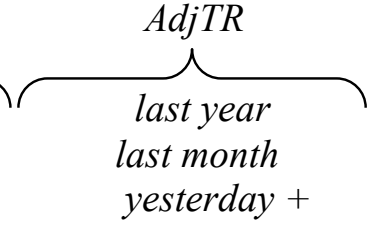

-á-B-ile

$\mathrm{P} 3$

Future

Figure 5: Division of P-domain into adjacent and distal TRs illustrating Bemba P1-P4

In fact, if we provide more context for the examples illustrating the scope possibilities of P1-P4, discussed earlier in (22-25), what we notice is that while P1 and $\mathrm{P} 2$ are more restricted with respect to adjacent vs. distal time regions in their scope relations, $\mathrm{P} 3$ and $\mathrm{P} 4$ are not. (34-35) are partial reproductions of (22-23) for P1 and $\mathrm{P} 2$, with specific contexts appended at the beginning of the sentence (the rest of the sentence is not given here for ease of exposition, as it exactly mirrors (22-23)). In this case, we notice that there is less freedom in the ability of P1 to take scope over P2 and vice versa, in contrast to between $\mathrm{P} 3$ and $\mathrm{P} 4 .^{24}$

(34) P1 scenario

a. cuungulo nomba...

7evening.COP now

'Its evening now. The girls who arrived (at P1) by bus should go and sing.'

b. Chisanga a-aci-fik-a uluceelo....

Chisanga 1SM-P2-arrive-FV 11 morning

'Chisanga arrived in the morning (at P2). Should he also go and sing?'

Answers to entailment: 7 speakers No; 2 speakers Yes

(35) P2 scenario

a. kaasuba nomba...

afternoon.COP nomba

'Its afternoon now. If Mutale bought food at P2 then we will go and swim.'

b. cuungulo nomba...

evening.COP now

'Its evening now. Mutale has just bought (at P1) food. Will we go and swim?'

Answers to entailment: 8 speakers No; 1 speaker Yes

\footnotetext{
${ }^{24}$ The copular in (34-35) is marked by vowel lengthening as well as the absence of the augment (initial

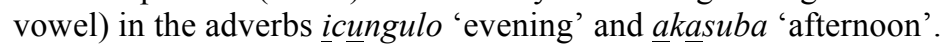


Thus, in these cases that specify the context more precisely, we see that there is less overlap between P1 and P2. Needless to say P3/P4 were unanimously excluded in these contexts. However, making the context more explicit for P3 and P4 (examples in 24-25) did not yield similar results but rather showed P3 and P4 being used in the same contexts. Thus, we see evidence for the division of time at the lower time level within $\mathrm{P} 1 / \mathrm{P} 2$ and also see a contrast in behaviour between $\mathrm{P} 1 / \mathrm{P} 2$, on the one hand, and $\mathrm{P} 3 / 4$ on the other.

This distribution is parallel to the future where F1/F2 mirror P1/P2 and F3 mirrors both $\mathrm{P} 3 / \mathrm{P} 4$ in terms of time region. The non-parallel distribution of F1/F2 vs. F3 suggests that these are organised in different domains i.e. F1/F2 is in the P-domain, while F3 is in the D-domain, as a different conceptual world that consists only of a distal time region. This division is depicted as in figure 6 below.

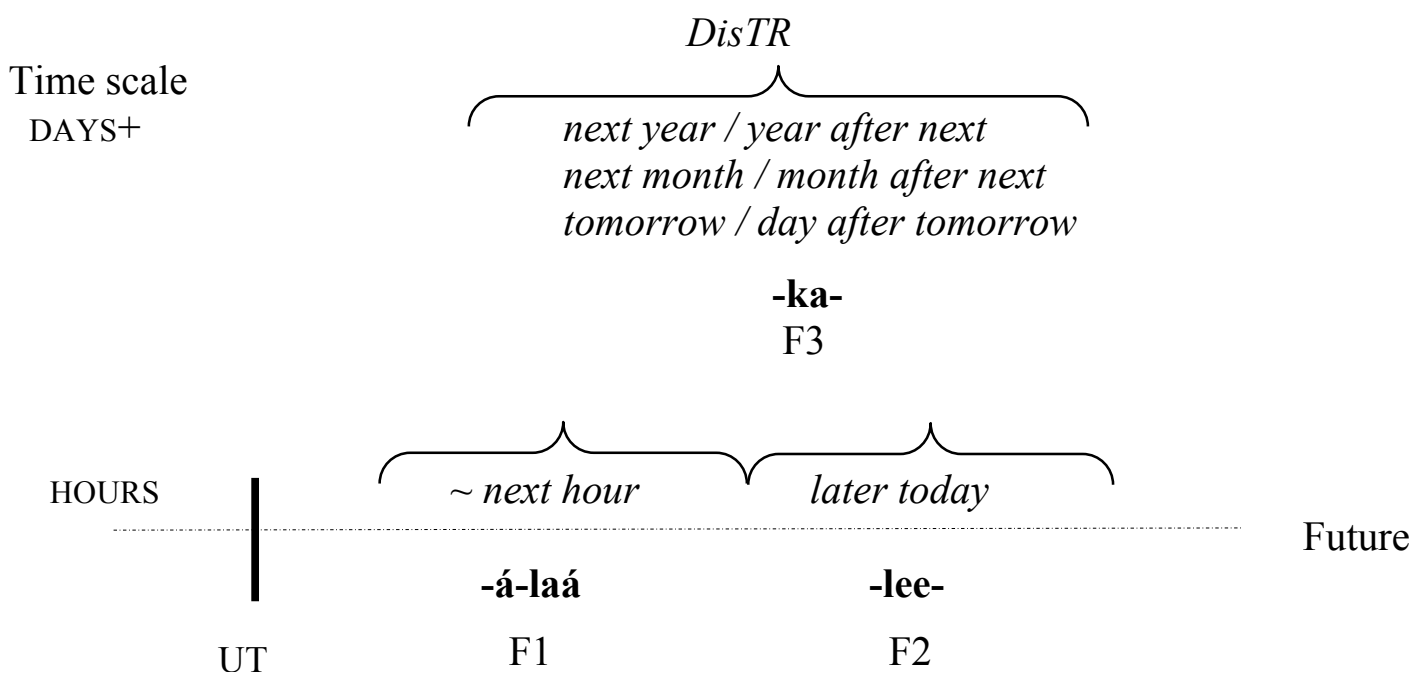

Figure 6: F1/F2 vs. F3 with non-coinciding TRs and in different domains

With a merged P3/P4 (correlating to F3) we lose the parallelism between $\mathrm{P} 1 / \mathrm{P} 2$ vs. $\mathrm{P} 3 / \mathrm{P} 4$ in Bemba and must assume that, just like in the future, this change results in the creation of a dissociated domain or exclusive cognitive world, for the merged P3/P4. This is depicted in figure 7 below.

In figure 7 , we see that the system started out with two time levels in the past, a lower time level up to 24 hours and a higher time level from a day onwards. The merger between P3 and P4 motivated by adjacency, form, tone loss and neutralization and system pressure, results in one form that does not coincide with the two time regions of $\mathrm{P} 1 / \mathrm{P} 2$ at the higher time level. This results in the reinterpretation of the merged $\mathrm{P} 3 / \mathrm{P} 4$ as a conceptually different world, represented in a dissociated domain. ${ }^{25}$ This direction of change - from P- to D-domain and not vice versa - is arguably motivated by the fact that temporal distinctions emerge in the P-domain, which is closely linked with the deictic centre and widen from that canonical domain to other conceptual worlds that are independent of the locus of the speech event.

\footnotetext{
${ }^{25}$ An anonymous reviewer points out that the two time scales can alternatively be viewed as based on different conceptualizations of the deictic center in the case of P1 and P3. For the time level of hours, it would be the UT; for the time level of days, it would be the day of the UT (not just the UT). From this perspective, P1 is the time region immediately prior to the UT (say an hour) and P3 is the time region immediately prior to today (i.e., yesterday). This distinction could then motivate the merger of P3 and P4 being construed as a separate domain and not a separate time scale. This broader construal of time is a viable option that will have to be pursued in future work.
} 
Figure 7 also depicts the future which has two time regions at the P-domain. We thus see two adjacent time regions in the P-domain, to the left (pasts) and to the right (futures) of the UT. Adjacent to F1 further in the future but within 24 hours is F2. F3 which has no internal time regions (only distal) is represented on a dissociated domain as discussed.

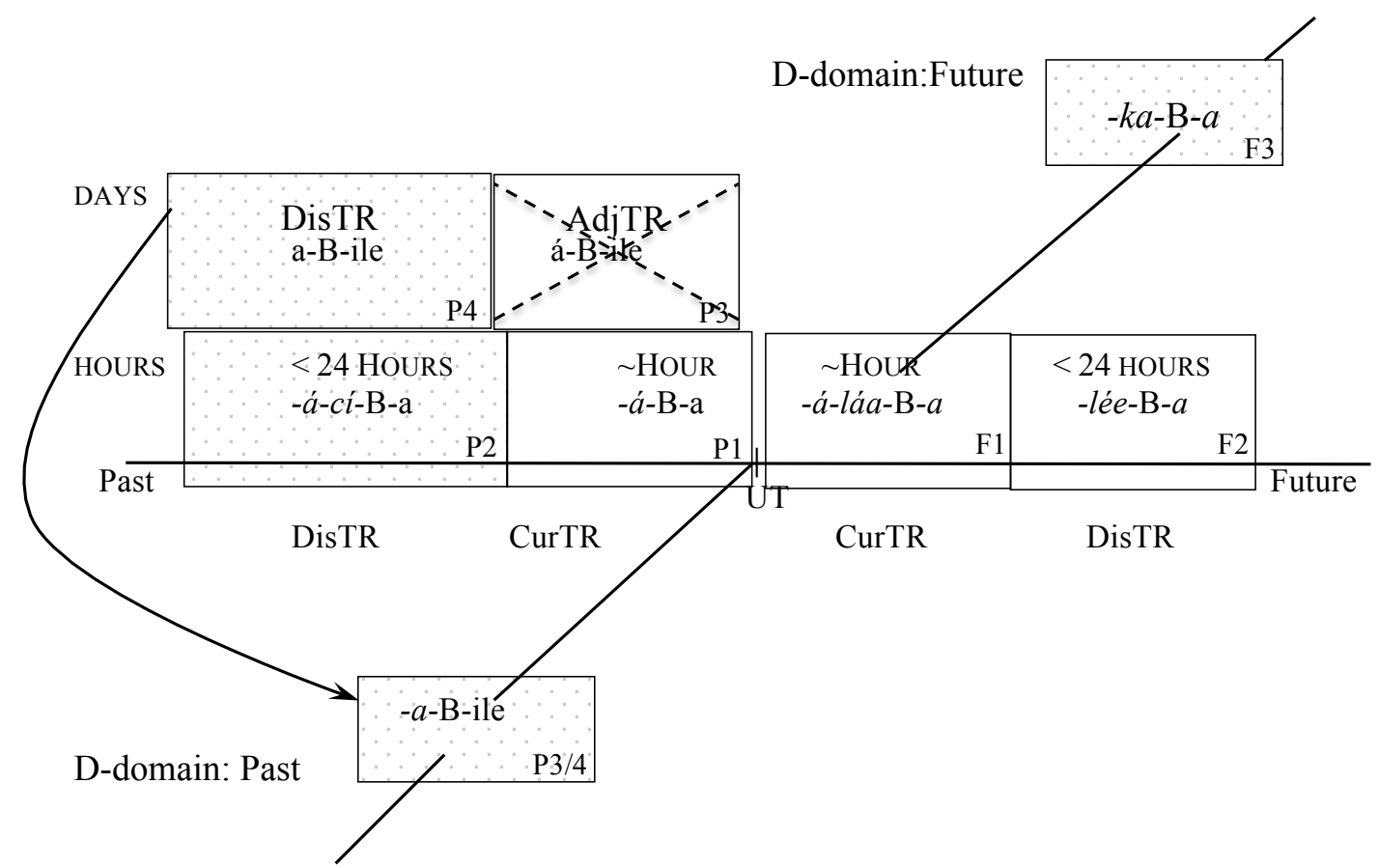

Figure 7: Reinterpretation of merged P3/P4 from P-to D-domain

This representation answers a number of questions that were raised earlier. P3 merges with $\mathrm{P} 4$ and not $\mathrm{P} 2$ because under this representation $\mathrm{P} 2$ and $\mathrm{P} 3$ are in fact not adjacent. The distinction that we saw earlier, dividing $\mathrm{P} 1 / 2$, on the one hand, and $\mathrm{P} 3 / \mathrm{P} 4$, on the other, is captured by the contrast between the lower time level and the higher time level. The idea of one past tense taking scope over another is best understood as following from contextual use of the relevant time region, allowing for a flexibility that captures the differing scope relations. The model thus affords this more nuanced interpretation. The contrast between $\mathrm{P} 1 / \mathrm{P} 2$ and the merged $\mathrm{P} 3 / 4$ is captured by the representation where the merged $\mathrm{P} 3 / \mathrm{P} 4$ gets reinterpreted as part of the D-domain because it no longer refers to actions that hold in the prevailing experiential past. The multi-dimensional representation also more precisely shows in what sense the change can be viewed as resulting in paradigm uniformity, since the past tense now mirrors the future. In terms of form, again we saw that $\mathrm{P} 1 / \mathrm{P} 2$ share more structure as do $\mathrm{P} 3 / \mathrm{P} 4$ which follows from their adjacent distribution. Notice that the representation allows us to capture that H-toned initial - $\dot{a}$ - represents an adjacent time frame, as we see this formative in P1, lost P3, disjoint P3, and F1. H-toned -áalso captures the closeness of P1 and P2 as being on the lower time level in a similar way that -ile does for the higher time level, so that we have form-meaning correlations that are neatly captured by the representation.

Figure 7 most closely represents those (older) speakers who still retain some passive knowledge of the $\mathrm{P} 3$ form and for whom the change is still in transition with some (memory) trace of P3 and P4 remaining on the P-domain despite an ongoing 
move of the merged form to the D-domain. This is captured by not totally obliterating $\mathrm{P} 3 / 4$ in the higher time level on the P-domain.

Recall, however, that a number of speakers seem to have replaced the conjoint P3 form with the disjoint P3 form -álii- $-a$. This would result in a reconfiguration of the $\mathrm{P}$-domain as depicted in figure $8 .{ }^{26}$ Here we see $\mathrm{P} 1$ on a lower time level of within an hour, and P2 and P3 on a higher time level over days and contrasting a hodiernal and a pre-hodiernal past, respectively. The representation also includes -lée- as present marker, in which case it is located at the UT with F1 immediately following in an adjacent time region. F2, which has the same form as the present, is represented on a higher time level within days. There is probably some internal division within F2 that is only tentatively represented here pending further investigation. ${ }^{27}$ Thus, the lower time level represents only those actions that occur within an hour, captured by three formatives: present, immediate past and immediate future. The higher time unit, on the other hand, covers a day ( + a few days) with the formatives for future of today, past of today and pre-hodiernal past. On the representation of form-meaning, figure 8 captures the fact that only those past formatives that end in $-a$ are represented on the P-domain, while -ile (for P4, not shown in figure 8) is conceptualised as dissociated from $-a$ final pasts.

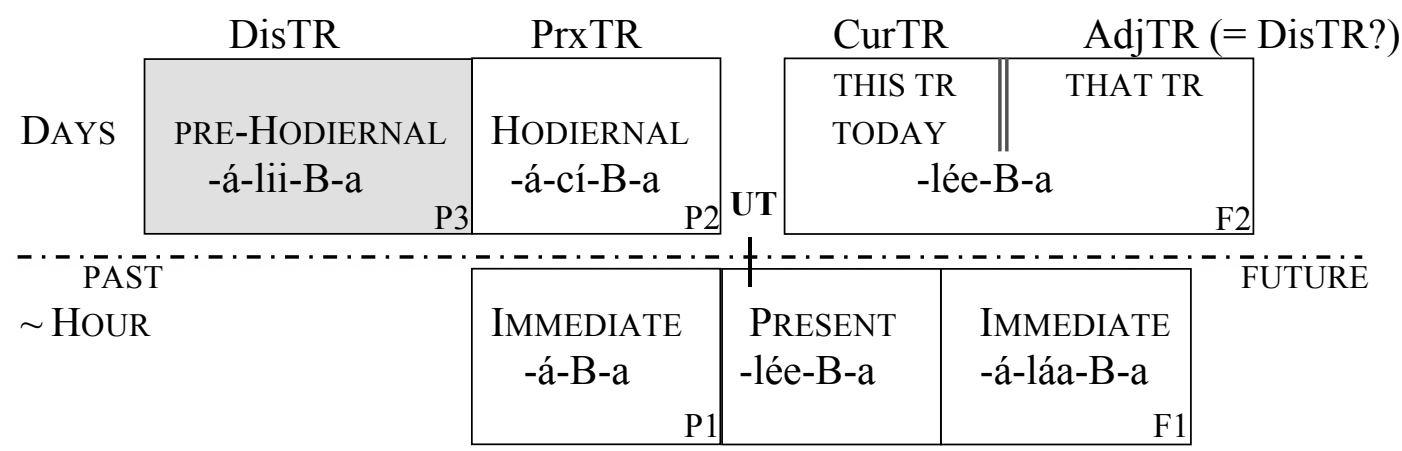

Figure 8: P-domain reconfiguration with disjoint P3 as sole P3 form

A remaining question is the representation of TAMs that still contrast conjointdisjoint forms, as well as those speakers who are merging the disjoint P3 and P4 forms, in a similar manner to the conjoint forms, at least in terms of function. ${ }^{28}$ This would require the representation to have more than one formative in each cell, or depending on associated aspectual restrictions and certainly focus, a way of capturing such considerations in the representation. If the conjoint-disjoint alternation, in the TAMs where it is present, interacts with aspect and focus providing the associated context of a particular past or future form in some cases (conjoint forms) but not in others (disjoint forms), then the question is whether this information needs to be apparent in the TAM representation. This is best understood in the context of the representation of aspectual and focal distinctions in a multi-dimensional model. For the current study an investigation is left to a future occasion but see some treatments of aspect in Botne (2010) and Crane (2012).

\footnotetext{
${ }^{26}$ PRXTR = proximate time region; CURTR $=$ current time region.

${ }^{27}$ An internal division within F2 tries to capture the fact that the same formative is used for the present, but more work is needed on this. Thanks to Bob Botne for discussion and for designing the graphics.

${ }^{28}$ The context of use of the P4 disjoint form also remains to be understood in the context of these changes. No claims are made about this here.
} 
A question that one might raise is whether, based on figure 7 , we predict eventual merger of $\mathrm{P} 1 / \mathrm{P} 2$ and F1/F2 which reside on the same domain and have a shared lower time level, with adjacent time regions. Apart from the alternative representation in figure 8 , the strongest argument against this currently comes from the scope relations between the two forms in each pair. In each case one is only allowed to scope over the other in 'real time' but based on context, it retains its temporal relation with the UT as either adjacent or distal time region. In this sense the functions of the two forms remain distinct. Of secondary relevance is the fact that the forms in each pair are distinct. Thus, although they may share one formative, there is always an additional morpheme in one that is absent from the other. Both forms in both pairs fall under those TAMs that have no $\mathrm{MH}$ and their tone patterns, in conjunction with their differing forms, afford no immediately recognizable import of tone on a possible merger. Finally, although a merger of $\mathrm{P} 1 / \mathrm{P} 2$ and F1/F2 would be consistent with paradigm uniformity it would not bring any particular advantage in this respect to the system, apart from perhaps making the system leaner, and so cannot be treated as a strong source of system pressure. However, it should be clear that the prediction of the representation would be that if a change were to occur the organisation adopted here (figure 7) predicts possible merger between P1/P2 and F1/F2 but not between P2 and merged P3/4 or between F2 and F3 because these do not share any major characteristics and they are never conceptualised as temporally adjacent, since they reside in different domains/conceptual worlds.

\section{CONCLUSION}

This paper has shown that a merger is taking place between P3 and P4 in both Northern and Copperbelt Bemba. This is occurring in both the conjoint and disjoint forms, but is more apparent in the conjoint form because in this case resultant homophonous forms result in the 'loss' of the P3 morphological form. The merger is instantiated in terms of function where the scope of P4 has been extended to cover P3. These facts have been accounted for from a multi-dimensional view of tense, as resulting from a change where $\mathrm{P} 3 / \mathrm{P} 4$ lose adjacent time region reference at the higher time level and only correlate to a distal time region. This change has then resulted in a reinterpretation of the merged $\mathrm{P} 3 / \mathrm{P} 4$ as residing in a dissociated domain. This representation already holds for the future, where F1/F2 are represented on the Pdomain but F3 is on the D-domain. The change therefore results in a parallel system in the past and future and can in this sense be viewed as also additionally motivated by system pressure towards paradigm uniformity. The motivation for the representation of $\mathrm{P} 1 / \mathrm{P} 2$ and $\mathrm{F} 1 / \mathrm{F} 2$, on the one hand, and merged $\mathrm{P} 3 / \mathrm{P} 4$ and $\mathrm{F} 3$, on the other, as in separate domains, comes from scope relations that support this distinction. This representation supports the contexts in which we have seen tonal interaction and morphological form similarity. In this sense, Botne's cognitive approach to the organisation of TAM systems provides a principled way of unifying the four main different factors identified as central to the observed merger of P3/P4, namely, phonological constraints, morphological form, semantic function, and paradigm uniformity. In addition, this paper has shown that this approach can be extended to account for language change.

A number of issues remain to be investigated in more detail before a complete picture of the Bemba TAM system can emerge. One issue is a comprehensive investigation of the changes going on in the conjoint-disjoint distinction and how they impact on the changes going on in the past tense, as briefly discussed. Within the past tense and beyond, it remains to be established whether the changes discussed here 
also apply to the negative forms and, in addition, how aspectual considerations interact with the foregoing discussions. Within Bemba dialectology, an investigation of the other main dialect, Luapula Bemba, would broaden the understanding of how widespread this change is. More broader yet, would be an investigation of other zone $\mathrm{M}$ languages to evaluate whether similar changes are also attested and what implications this has for the current analysis, which has sought language internal motivations and explanations. These areas will no doubt provide a good basis for future research.

\section{ACKNOWLEDGEMENTS}

This work was funded by a British Academy small grant number SG102315 held between 2011-2013 which is gratefully acknowledged. Thanks to all consultants and for discussion, significant insight and comments on an earlier version from Bob Botne, Mary Dalrymple and Axel Fleisch. Thanks also to audiences from a number of conferences and workshops and two anonymous reviewers whose comments have helped clarify the argument developed immensely. All errors are the responsibility of the author. 


\section{APPENDIX A}

Forms starting with $t a$ - indicate negative forms.

\begin{tabular}{|c|c|c|c|c|c|c|}
\hline & PERFECTIVE & IMPERFECTI & & PERSISTIVE & & ANTERIOR \\
\hline $\begin{array}{l}\text { Remote Past } \\
\text { (P4) (timed) }\end{array}$ & 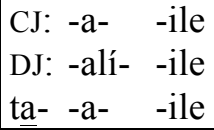 & $\begin{array}{l}\text {-alée- } \\
\text { ta- -alée }\end{array}$ & $\begin{array}{l}-\mathrm{a} \\
-\mathrm{a}\end{array}$ & -ácíli-SM-alee- & $-\mathrm{a}$ & 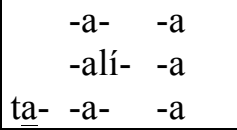 \\
\hline $\begin{array}{l}\text { Recent Past } \\
\text { (P3) }\end{array}$ & $\begin{array}{lll}\text { CJ: -á- } & \text {-ile } \\
\text { DJ: -álii- } & -a \\
\text { ta- } & \text {-a- } & \text {-ile }\end{array}$ & $\begin{array}{l}\text {-álée- } \\
\text { ta- -álée }\end{array}$ & $\begin{array}{l}-a \\
-a\end{array}$ & -ácíli-SM-álee- & $-a$ & \\
\hline $\begin{array}{l}\text { Earlier today Past } \\
\text { (P2) }\end{array}$ & $\begin{array}{r}\text {-ácí- -a } \\
\text { ta- -ácí- -a } \\
\end{array}$ & $\begin{array}{l}\text {-áciláa- } \\
\text { ta- -áciláa- }\end{array}$ & $\begin{array}{l}-\mathrm{a} \\
-\mathrm{a} \\
\end{array}$ & -ácíli-SM-acílaa- & $-a$ & \\
\hline $\begin{array}{l}\text { Immediate Past } \\
\text { (P1) }\end{array}$ & $\begin{array}{ll}\text { CJ: -á- } & -a \\
\text { DJ: -áa- } & -a \\
\end{array}$ & & & & & \\
\hline Zero & 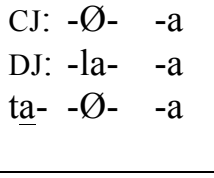 & $\begin{array}{l}\text {-lée- } \\
\text { ta- -leé- }\end{array}$ & $\begin{array}{l}-a \\
-a\end{array}$ & $\begin{array}{l}\text { CJ: -cíli-SM-Ø- } \\
\text { DJ: -cíli-SM-la- }\end{array}$ & $\begin{array}{l}-\mathrm{a} \\
-\mathrm{a}\end{array}$ & $\begin{array}{ll}\text { CJ: } & -\varnothing-\text {-ile } \\
\text { DJ: náa--Ø--a } \\
\text { ta- } & -a-\text {-a } \\
\text { ta- } & -\varnothing-\text {-ile }\end{array}$ \\
\hline $\begin{array}{l}\text { Immediate Future } \\
\text { (F1) }\end{array}$ & 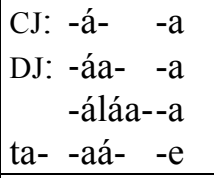 & ta- -aá- & $\begin{array}{l}-\mathrm{a} \\
-\mathrm{e} \\
\end{array}$ & -cíli-SM-akuláa- & $-\mathrm{a}$ & \\
\hline $\begin{array}{l}\text { Later today Future } \\
\text { (F2) }\end{array}$ & $\begin{array}{r}\text {-lée- } \\
\text { ta- -aa- } \\
\text { ta }\end{array}$ & & & & & \\
\hline $\begin{array}{l}\text { After today Future } \\
\text { (F3) }\end{array}$ & $\begin{array}{r}-k a-\quad-a \\
\text { ta- } \\
\end{array}$ & $\begin{array}{l}\text {-kaláa- } \\
\text { ta- -akalée }\end{array}$ & $\begin{array}{l}-\mathrm{a} \\
-\mathrm{a} \\
\end{array}$ & -cíli-SM-kaláa- & $-\mathrm{a}$ & \\
\hline
\end{tabular}

Table 1: Bemba TAMs (adapted from Nurse 2008)

\section{REFERENCES}

Bastin, Yvonne, 1983. La finale verbale-ide et l'imbrication en Bantou. Sciences Humaines 114. Tervuren: Annales du Museé Royal de l'Afrique Centrale.

Bickmore, Lee, \& KulA, NANCY, C. 2013. Ternary spreading and the OCP in Copperbelt Bemba. Studies in African Linguistics 42(2): 101-132.

Boersma, PAul \& WeEnINK, DAVID, 2014. Praat. www.praat.org, accessed $28^{\text {th }}$ August 2014.

DE BloIS, KoRnelis, F. 1970. The augment in the Bantu languages. Tervuren: Royal Museum for Central Africa.

Botne, Robert, 2003. Dissociation in tense, realis, and location in Chindali verbs. Anthropological Linguistics 45: 390-412.

Botne, RoBert, 2006. A Grammatical sketch of the Lusaamia verb (with H. Ochwada \& M. Marlo). Cologne: Rüdiger Köppe Verlag.

Botne, Robert, 2010. Perfectives, perfects \& pasts! Oh my! On the semantics of -ile in Bantu. Africana Linguistica 16: 31-63.

Botne, RoBert, 2012. Remoteness distinctions. In R. Binnick (ed.), The Oxford Handbook of Tense and Aspect. Oxford: Oxford University Press, 536-562.

Botne, Robert, \& Kershner, Tiffany, L. 2008. Tense and cognitive space in Bantu Languages. Cognitive Linguistics 19(2): 145-218. 
Buell, LESTON, 2006. The Zulu conjoint/disjoint verb alternation: Focus or constituency? ZAS Papers in Linguistics 43: Papers in Bantu Grammar and Description, 8-30.

Crane, THERA, 2012. Completion and dissociation in Totela tense and aspect. In Michael R. Marlo, Nikki B. Adams, Christopher R. Green, Michelle Morrison \& Tristan M. Purvis (eds.), Selected Proceedings of the 42nd Annual Conference on African Linguistics, 208-220. Somerville, MA: Cascadilla Proceedings Project.

COMrIE, Bernard, 1976. Aspect. Cambridge: Cambridge University Press.

COMrie, Bernard, 1985. Tense. Cambridge: Cambridge University Press.

Corbett, Greville, G. \& Fraser, Norman, M. 1993. Network morphology: a DATR account of Russian nominal inflection. Journal of Linguistics 29: 113-142.

Creissels, Denis, 1996. Conjunctive and disjunctive verb forms in Setswana. South African Journal of African Languages 16.6: 109-115.

CREISSELS, DENIS, 2012. Conjoint and Disjoint verb forms in Tswana and other Bantu Languages. Ms., University of Lyon.

DAHL, ÖSTEN, 1985. Tense and Aspect Systems. Oxford: Blackwell.

Devos, Maud, \& VAn Der Wal, JenneKe, 2014. (eds.) COME and GO: Off the beaten grammaticalisation path. Berlin/Boston: Mouton de Gruyter.

Givón, Talmy, 1972. Studies in ChiBemba and Bantu Grammar. Studies in African Linguistics, supplement 3.

Givón, TALmY, 1975. Focus and the scope of assertion: Some Bantu evidence. Studies in African Linguistics 6.2: 185-205.

Goldsmith, John, 1979. Autosegmental Phonology. New York: Garland.

Guthrie, Malcom, 1967-71. Comparative Bantu. 4 vols. Farnborough: Gregg.

Hoch, E. Rev. 1963. A Bemba Grammar with Exercises. Chinsali: Language Centre Ilondola.

Hyman, Larry, M. 1995. Minimality and Prosodic Morphology of ChiBemba imbrication. Journal of African Languages and Linguistics 16: 3-39.

Hyman, Larry, M. 2012. Disentangling Conjoint, Disjoint, Metatony, Tone Cases, Augments, Prosody, and Focus in Bantu. UC Berkeley Phonology Lab Annual Report.

HYMAn, LARRY, M. \& VAN DER WAL, JENNEKe, to appear. (eds.) The conjoint/disjoint alternation. Berlin: Mouton de Gruyter.

KabingA, Moonde, 2010. A Comparative study of the Morphosyntax and Phonetics of Town Bemba and Standard Bemba of the Copperbelt, Zambia. MA thesis, University of Cape Town.

KashoKi, Mubanga, E. 1972. Town Bemba: A sketch of its main characteristics. African Social Research 13: 161-186.

Kershner, Tiffany, L. 2002. The verb in Chisukwa: Aspect, tense, and time. Doctoral dissertation. Indiana University, Bloomington.

Kiso, Andrea, 2012. Tense and Aspect in Chichewa, Citumbuka and Cisena. PhD. thesis, Stockholm University.

KulA, NANCY, C. 2002. The phonology of verbal derivation in Bemba. LOT Dissertation series 65.

Kula, NANCY, C. 2008. Derived Environment Effects: A representational approach. Lingua 118(9): 1328-1343.

KulA, NANCY, C. to appear. The conjoint-disjoint alternation and phonological phrasing in Bemba. In L.M. Hyman and J. van der Wal (eds.) The conjoint/disjoint alternation. Berlin: Mouton de Gruyter. 
Kula, Nancy, C. \& Bickmore, Lee, 2015. Prosodic phrasing in Copperbelt Bemba. Phonology 32.1: 147-176.

Kula, Nancy, C. \& Braun, Bettina, 2015. Mental representation of tonal spreading in Bemba: Evidence from elicited production and perception. Southern African Linguistics and Applied Language Studies 33(3): 307-323.

MAHO, Jouni, 2009. The online version of the new updated Guthrie list, a referential classification of the Bantu Languages. http://goto.glocalnet.net/mahopapers/nuglonline.pdf (accessed 23rd August 2015).

MANN, Michael, 1977. An outline of IciBemba Grammar. In Kashoki M.E. (ed.), Language in Zambia: Grammatical Sketches. Lusaka: Institute for African Studies. Reprinted 1999, Lusaka: Bookworld Publishers.

Meeussen, Achille, E. 1959. Essai de Grammaire Rundi. Tervuren: Annales du Museé Royal de 1'Afrique Centrale, Série Sciences Humaines 24.

Meeussen, Achille, E. 1967. Bantu grammatical reconstructions. Africana Linguistica 3: 81-121.

Nurse, DereK, 2003. Aspect and tense in Bantu languages. In Nurse, D. and G. Philippson (eds.) The Bantu Languages. London: Routledge, 90-102.

Nurse, DereK, 2006. Focus in Bantu. ZAS Papers in Linguistics 43: Papers in Bantu Grammar and Description, 189-207.

Nurse, DereK, 2008. Tense and Aspect in Bantu. Oxford: Oxford University Press.

Nurse, Derek, \& Philippson, GÉRARd, 2006. Common tense aspect markers in Bantu. Journal of African Languages and Linguistics, 155-196.

ODDEN, DAVID, 1986. On the role of the Obligatory Contour Principle in phonological theory. Language 62: 353-383.

Odden, David, \& Bickmore, LeE, 2014. Melodic tone in Bantu: Overview. Africana Linguistica 20: 3-14.

ReICHENBACH, Hans, 1947. Elements of symbolic logic. New York: The Macmillan Company.

VAN SAMBeeK, J. 1955. A Bemba Grammar. London: Longmans, Green and Co.

SHARMAN, John, C. 1956. The tabulation of tenses in a Bantu language (Bemba: Northern Rhodesia). Africa 26: 29-46.

Sharman, John, C. and Meeussen, Achille, E. 1955. The representation of structural tones, with special reference to the tonal behavior of the verb in Bemba, Northern Rhodesia. Africa: Journal of the International African Institute 25.4: 393-404.

Smith, Carlota, S. 1997. The Parameter of Aspect. Dordrecht: Kluwer Academic Publications.

SPENCER, ANDREW, 2013. Lexical relatedness. Oxford: Oxford University Press.

SPITUlNIK, DeBRA, 1998. The Language of the City: Town Bemba as Urban Hybridity. Journal of Linguistic Anthropology 8(2): 30-59.

Stump, GRegORY, T. 2001. Inflectional Morphology: A Theory of Paradigm Structure. Cambridge: Cambridge University Press.

VAN DER WAL, JENNEKE, 2006. The disjoint verb form and an empty immediate after verb position in Makhuwa. ZAS Papers in Linguistics 43: Papers in Bantu Grammar and Description, 233-256.

VAN DER WAL, JENNEKE, 2009. Word order and information structure in MakhuwaEnahara. PhD thesis, University of Leiden.

VAN DER WAL, JENNEKE, 2011. Focus excluding alternatives: Conjoint/disjoint marking in Makhuwa. Lingua 121: 1734-1750. 
YoNEDA, NoBUKo, 2009. Information structure and sentence formation in Matengo. In Manghyu, P. (ed.) Current issues in unity and diversity of languages (Selected papers from CIL 18). Linguistic Society of Korea, 443-453. 